\title{
The structure-based reaction mechanism of urease, a nickel dependent enzyme: tale of a long debate
}

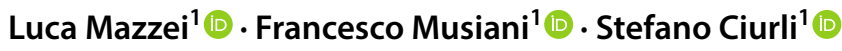

Received: 30 May 2020 / Accepted: 29 June 2020 / Published online: 18 August 2020

(c) The Author(s) 2020

\begin{abstract}
This review is an attempt to retrace the chronicle that starts from the discovery of the role of nickel as the essential metal ion in urease for the enzymatic catalysis of urea, a key step in the biogeochemical cycle of nitrogen on Earth, to the most recent progress in understanding the chemistry of this historical enzyme. Data and facts are presented through the magnifying lenses of the authors, using their best judgment to filter and elaborate on the many facets of the research carried out on this metalloenzyme over the years. The tale is divided in chapters that discuss and describe the results obtained in the subsequent leaps in the knowledge that led from the discovery of a biological role for Ni to the most recent advancements in the comprehension of the relationship between the structure and function of urease. This review is intended not only to focus on the bioinorganic chemistry of this beautiful metal-based catalysis, but also, and maybe primarily, to evoke inspiration and motivation to further explore the realm of bio-based coordination chemistry.
\end{abstract}

Keywords Nickel · Urease · Catalytic mechanism · Crystal structure $\cdot$ Sporosarcina pasteurii $\cdot$ Klebsiella aerogenes . Helicobacter pylori

\section{Introduction}

Urease (urea amidohydrolase E.C. 3.5.1.5) is a nickeldependent enzyme found in a large variety of organisms, including plants, algae, fungi, and several prokaryotes $[1$, 2]. It is critically involved in the mineralization step of the global nitrogen cycle, being able to catalyze the rapid hydrolytic decomposition of urea to produce ammonia and carbamate, the latter eventually decomposing spontaneously into a second molecule of ammonia and bicarbonate (Scheme 1) [3-6]. This catalytic activity triggers a rapid overall $\mathrm{pH}$ increase of the milieu (Scheme 2) that has negative effects both on human health [7] and agriculture [8].

This alkalization effect is utilized by numerous human pathogenic microorganisms that exploit urease as a virulence factor to infect and colonize the host $[7,9,10]$. The priority pathogen list indicated by the World Health Organization for the research and development of new antibiotics

Stefano Ciurli

stefano.ciurli@unibo.it

1 Laboratory of Bioinorganic Chemistry, Department of Pharmacy and Biotechnology, University of Bologna, Viale G. Fanin 40, 40127 Bologna, Italy
[11] includes urease-dependent antibiotic-resistant bacteria, several of which are involved in bacterial infections of the respiratory apparatus, and it is remarkable that half of patients who died of the recent COVID-19 epidemics in Wuhan (China) became co-infected with bacteria in the lungs and also required antibiotics [12]. In particular, Helicobacter pylori infection, affecting large portions of the entire human population, causes a series of gastrointestinal diseases, including chronic gastritis, peptic ulcer and eventually gastric cancer [13]. In H. pylori, urease represents up to $10 \%$ of the total protein content [14] and is essential for the survival of this human pathogen in the acidic gastric environment by maintaining its cytoplasmic $\mathrm{pH}$ close to neutral $[15,16]$. In Staphylococcus aureus, a human pathogen that causes acute and chronic infections resulting in significant morbidity, urease is crucial to $\mathrm{pH}$ homeostasis and viability in urea-rich environments, rendering it an important factor required for persistent murine renal infections [17]. Mycobacterium tuberculosis, the etiologic agent of the tuberculosis disease, is an intracellular bacterium that infects macrophages, living inside their phagosomes. In this environment, its survival depends on the activity of nickel-dependent urease. In particular, urea hydrolysis is essential for bacterial survival, since it 


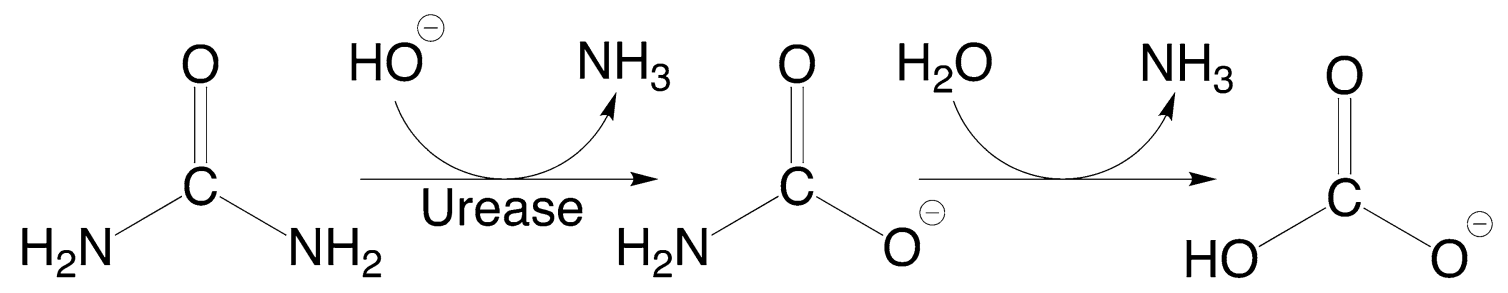

Scheme 1. Enzymatic steps for the urea hydrolysis

Scheme 2. Overall reaction of urea hydrolysis

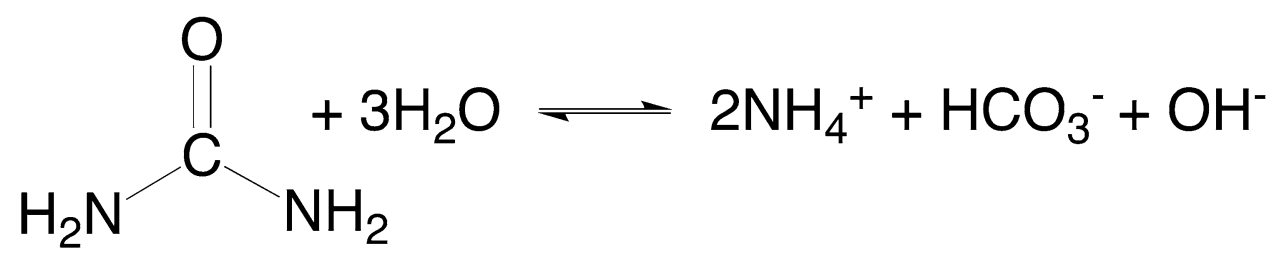

contributes to nitrogen availability and environmental $\mathrm{pH}$ modulation [18]. Moreover, ammonia derived from this reaction can block the phagosome-lysosome fusion, being an important defensive mechanism against the immune system of the host [19]. The alkalizing effect of the urease activity within the mycobacterium-containing vacuole in resting macrophages, and the role for the urease activity in $M$. tuberculosis nitrogen metabolism that could be crucial for the pathogen's survival in nutrient-limited microenvironments where urea is the sole nitrogen source, have been demonstrated [20]. Yersinia enterocolitica and $Y$. pseudotuberculosis, isolated from different sources, including food, clinical material and certain animals, can cause acute or chronic foodborne disease manifested by a variety of clinical symptoms, and in Europe yersiniosis is the third most common food-borne gastroenteritis after campylobacteriosis and salmonellosis. Ureases appear to play a vital role in the survival of $Y$. enterocolitica cells in the natural environment by degrading urea in the soil and water, which is utilized by this saprophyte as the sole nitrogen source [21]. Finally, several fungi pathogenic to humans have urease activity, among which is Cryptococcus neoformans, whose urease appears to be a component of the composite cryptococcal virulence phenotype, suggesting that urease inhibitors or vaccines may be useful in the treatment or prevention of cryptococcosis [22].

In other settings, the widespread presence of urease in soils, both inside living cells of plants and microbes as well as extracellular enzyme adsorbed onto organic and inorganic soil components, poses significant environmental and economic problems: it causes the release of large amounts of ammonia $\mathrm{N}$ in the atmosphere, thus negatively affecting the efficiency of urea-based soil fertilization, inducing plant damage by ammonia toxicity and soil $\mathrm{pH}$ increase [8] with the consequent formation of airborne particulate matter
(PM) that contributes to atmospheric pollution [23]. It has been found that the presence of ultrafine PM has been significantly associated with an increase of the mortality rate in the SARS (severe acute respiratory syndrome) epidemics in the early 2000s [24], suggesting that containment of air pollution through well-managed agricultural activities is absolutely necessary not only for the environment but also for human health.

The central role of this enzyme in such important aspects of the world society at large has been of great stimulus for the scientific community to extensively investigate and deepen the comprehension of the structure-function relationships of urease, a mandatory prerequisite for the discovery of new chemicals able to challenge its negative effects. The availability of information on the genetic organization of DNA responsible for urease expression, as well as the molecular structures of native ureases and urease-inhibitor complexes, has led to significant steps towards these goals. A substantial improvement in the knowledge of the molecular basis of the catalytic mechanism, including the role of nickel, has allowed us to obtain an essentially complete picture of the enzymatic mechanism. The following paragraphs are a historical excursus on the proposed models for the breakdown of urea catalyzed by urease, the main focus of this monograph.

\section{Brief history of urease milestones (1864- 2010)}

The history of urease can be dated back to 1864, when Van Tieghem isolated the first ureolytic microorganism, Micrococcus ureae [25]. Five years later Frédéric Alphonse Musculus isolated the first ureolytic enzyme, called "soluble ferment" and able to produce ammonia in putrid urine [26, 
A

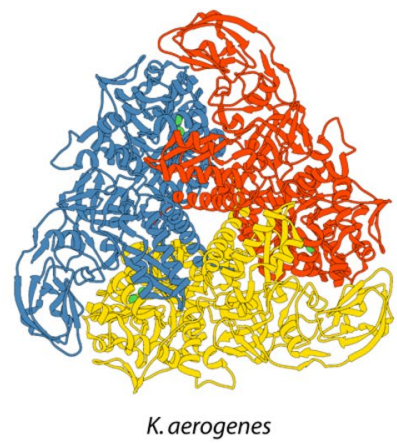

B

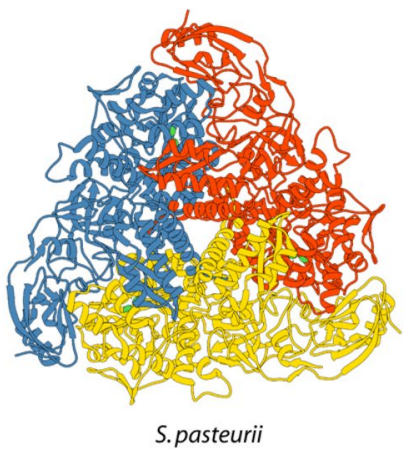

C
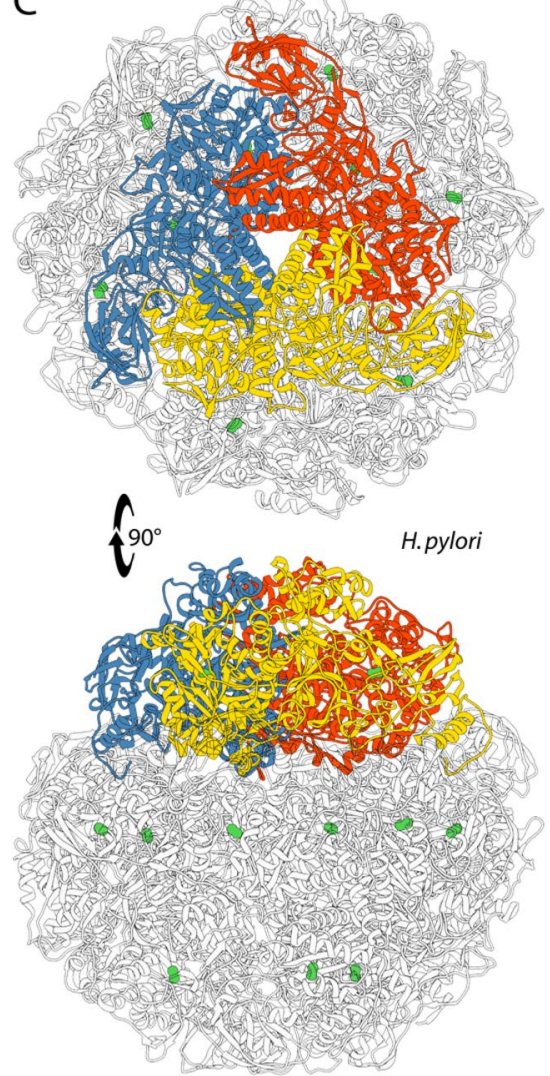

D
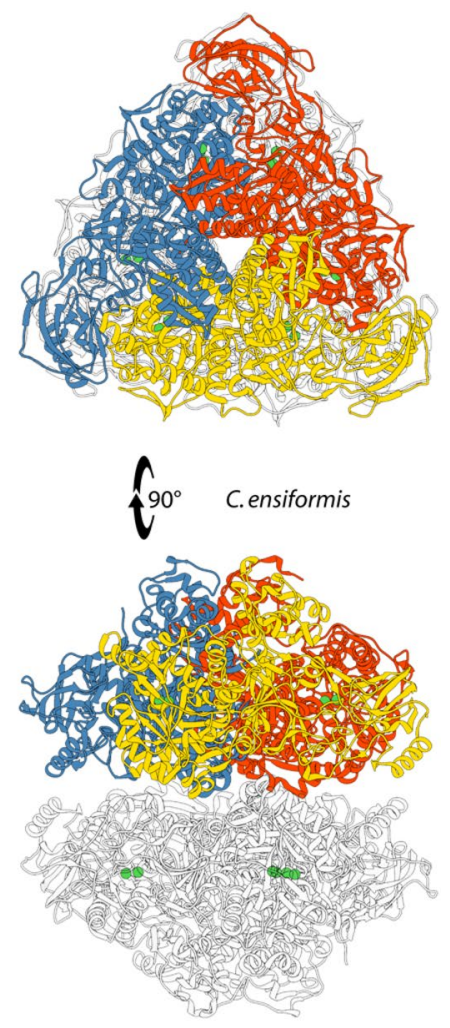

Fig. 1 Ribbon diagram of urease from a $K$. aerogenes (PDB code: 1EJZ), b S. pasteurii (PDB code: 4CEU), c H. pylori (PDB code: 1E9Z), and $\mathbf{d} C$. ensiformis (jack bean, PDB code: 3LA4). Ribbon colors evidence the chains composing the trimer constituting the min- imal quaternary structure of urease. $\mathrm{Ni}$ (II) ions are reported as green spheres. The bottom panels of $\mathbf{c}$ and $\mathbf{~}$ are rotated by $90^{\circ}$ around the horizontal axis vs. the top panels
27]. In 1926, James B. Sumner, working on the seeds of Canavalia ensiformis (jack bean) with the aim of defining the chemical nature of enzymes, obtained isolated protein crystals possessing, using his own words, "to an extraordinary degree the ability to decompose urea into ammonium carbonate". This property, identical to the already established ability of urease, paved the way for the first demonstration that enzymes were proteins [28]. This discovery led Sumner to receive the Nobel Prize in Chemistry in 1946. During the 1950s to the 1970s, a very fruitful period for the improvement of the knowledge on the structural and biochemical information of enzymes, key aspects as proficiency, stability, and high specificity of urease were established [29].

In 1975, jack bean urease was demonstrated to require nickel for the catalysis, providing the first model for the biological role of this metal as an enzyme prosthetic group [30]. A personal account by Nick Dixon on the discovery of the role of nickel in urease has been published [31].

Twenty years later, the first X-ray crystal structure of urease (from the enzyme Klebsiella aerogenes (KAU), recombinantly obtained using Escherichia coli cell strains) was determined [32]. This important achievement was followed by the determination of the urease structure from the soil bacterium Sporosarcina pasteurii (SPU) [33] (formerly known as Bacillus pasteurii from older taxonomies) and that of urease from Helicobacter pylori (HPU), a human pathogen [34]. The structure of the first plant urease, from Canavalia ensiformis (JBU), exactly the same protein that was crystallized by Sumner 85 years earlier, was then reported in 2010 (Fig. 1) [35].

Together, these structures provided a general description of the structure-function relationships of ureases. Nowadays it has been well-established that the overall protein scaffold is conserved among ureases from different sources (Fig. 1). In most bacterial ureases, the quaternary structure is made of a $(\alpha \beta \gamma)_{3}$ trimer of trimers with three identical active sites, each located in the $\alpha$ subunits. Some other bacterial enzymes show a larger $\beta$ subunit resulting from the fusion of the original $\beta$ and $\gamma$ subunits, forming $(\alpha \beta)_{3}$ trimers. In the special case of urease from Helicobacter pylori (HPU), four $(\alpha \beta)_{3}$ trimers form the spheroid-shaped tetramer of trimers 


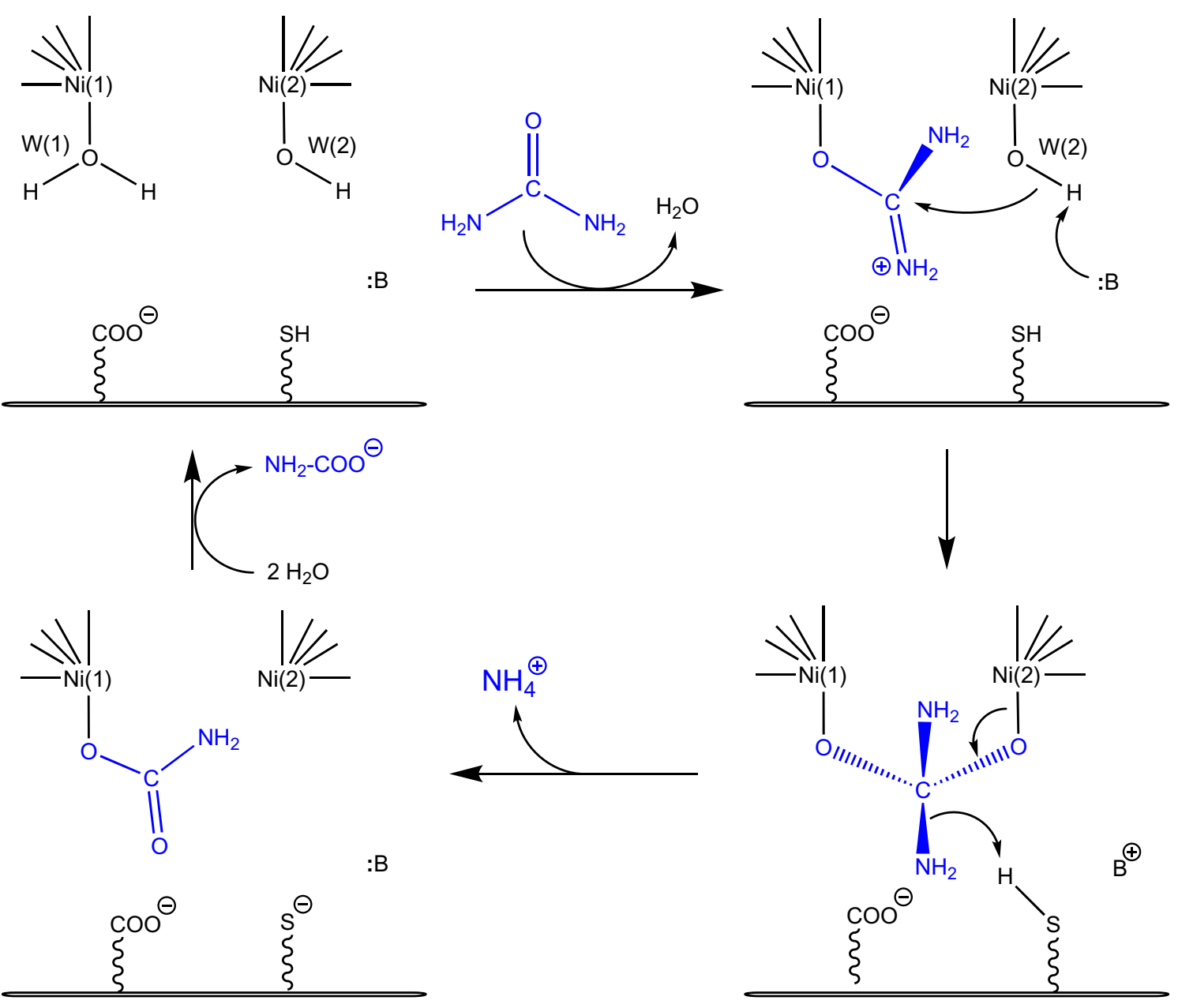

Scheme 3. Urease mechanism proposed by Blakeley and Zerner (adapted from ref [4])

$\left[(\alpha \beta)_{3}\right]_{4}$, containing twelve independent active sites. Finally, plant ureases are generally made up of a dimer of homotrimers $\left(\alpha_{3}\right)_{2}$, where the $\alpha$ subunit is derived from the fusion of the corresponding $\alpha, \beta$ and $\gamma$ subunits found in bacteria (Fig. 1). The knowledge of the structural properties of the protein architecture did not lead, however, to an immediate general consensus on the reaction mechanism, also because of initial significant differences in the interpretation of the electron density maps derived from X-ray diffraction. These early controversies have now been resolved and what follows is an historic account of the evolution of the consensus on the catalytic steps in the urease mechanism.

\section{The Australian mechanism (1975-1980)}

In the 1970s, a major discovery in the bioinorganic chemistry field was achieved by Dixon, Blakeley and Zerner, researchers working at the University of Queensland (Australia), who first demonstrated the requirement of two $\mathrm{Ni}$ atoms per each of the six subunits of JBU to perform its catalytic activity [30]. At that time, there was no any other information available on the overall structure of ureases, nor any model was developed to describe the activation of carboxylic acid amides towards $\mathrm{Ni}$-dependent hydrolysis or, more in general, metal-ion driven hydrolysis of urea. In this pioneering work, the formulation of a mechanistic hypothesis driven by both nickel ions found in the active site (Scheme 3) was elaborated by analyzing the reactivity of different substrates as catalyzed by the enzyme [4].

In particular, the authors proposed that, in the resting state of the enzyme, one of the two active site nickel ions [Ni(1) and $\mathrm{Ni}(2)$, hereafter] would coordinate a water molecule $[\mathrm{W}(1)]$ and the other a hydroxide ion $[\mathrm{W}(2)]$. The initial step of this mechanism entailed the replacement of $\mathrm{W}(1)$ by a urea molecule, bound to $\mathrm{Ni}(1)$ in a monodentate mode using its carbonyl oxygen. Urea would be additionally stabilized through the interaction of one of its $\mathrm{NH}_{2}$ groups with a nearby negatively charged carboxylate group from aspartate or glutamate residues. The subsequent nucleophilic attack 
on the urea carbonyl $\mathrm{C}$ atom would be carried out by the $\mathrm{Ni}(2)$-coordinated hydroxide, to form a tetrahedral intermediate that would readily collapse to form carbamate, which would remain, at this stage, coordinated to $\mathrm{Ni}(1)$ through one of its $\mathrm{O}$ atoms. Carbamate was indeed known to be the product of the urease-catalyzed hydrolysis of urea, evidence that excluded the possibility of an elimination mechanism [3]. The concomitant production of an ammonium cation would be facilitated by an active-site thiol group from a nearby cysteine residue [36] acting as a general acid catalyst. In the last step, the resting state of the enzyme would be regenerated by the entrance of water molecules and release of carbamate. Remarkably, the authors state that "[this] detailed mechanism requires that the two nickel ions ... be within $\sim 6 \AA$ of each other", a conclusion that will be proven absolutely correct.

\section{A mechanism based on spectroscopic and kinetic evidence (1980-1996)}

In the fifteen years following the Australian hypothesis, the architecture of the active site of the enzyme was investigated using spectroscopic studies. UV-visible absorption spectra were interpreted as indicating the presence of $\mathrm{Ni}$ (II) ions in a six-coordinated pseudo-octahedral geometry in the active site of JBU, while the presence of four- and fivecoordinated $\mathrm{Ni}(\mathrm{II})$ ions was considered unlikely [30, 37, 38]. X-ray absorption spectroscopic (XAS) studies were also interpreted as suggesting the presence of pseudo-octahedral $\mathrm{Ni}$ (II) ions coordinated, on average, to three histidine $\mathrm{N}$ atoms at $2.04 \AA$, two $\mathrm{O}$ atoms at $2.07 \AA$, and one $\mathrm{O}$ atom at $2.25 \AA[39,40]$. Magnetic susceptibility studies using JBU were then interpreted with the presence of a metal cluster containing two high-spin $(S=1)$ octahedrally coordinated $\mathrm{Ni}(\mathrm{II})$ ions, with a weak anti-ferromagnetic coupling [41]. This result confirmed the early assumptions of the presence of two closely-spaced $\mathrm{Ni}$ (II) ions [4], and was further supported by the diamagnetism observed upon binding of the competitive inhibitor 2-mercaptoethanol to JBU, resulting in a strong anti-ferromagnetically coupled $\mathrm{Ni}(\mathrm{II})-\mathrm{Ni}$ (II) dimer bridged by a thiolate $S$ atom [41], and by the evidence that this binding involved a ligand exchange in the coordination sphere of nickel [42]. This result was challenged by a later study [43]. Subsequent higher quality XAS data on JBU were interpreted with a model involving the presence of $\mathrm{Ni}(\mathrm{II})$ ions bound to five or six (N/O) donor ligands at an average distance of $2.06 \AA$ in a distorted octahedral geometry [42], largely confirming the earlier study [39, 40]. This conclusion was further refined using evidence based again on XAS, which suggested the presence, both in JBU and in $\mathrm{KAU}$, of two penta-coordinated $\mathrm{Ni}$ (II) ions in a $\mathrm{Ni}(\mathrm{N}$ His $)_{x}(\mathrm{~N} / \mathrm{O})_{5-x}(x=2$ or 3$)$ ligand environment, separated by
$3.26 \AA$ in the presence of 2-mercaptoethanol, assumed to bridge the two metal ions through the thiolate $\mathrm{S}$ atom [44]. Shortly after, an XAS study on SPU was interpreted as indicating the presence, in the enzyme active site, of two hexacoordinated $\mathrm{Ni}(\mathrm{II})$ ions with a $\mathrm{Ni}(\mathrm{N}-\mathrm{His})_{2}(\mathrm{~N} / \mathrm{O})_{4}(x=2$ or 3$)$ pseudo-octahedral geometry and an average nickel-ligand distance of $2.03 \AA$ [45]. These preliminary structural information were complemented by kinetics studies on KAU: the $\mathrm{pH}$-dependent activity of the native enzyme, which followed a bell-shaped curve, was shown to be altered in the case of chemical modifications and mutants of $\alpha$ Cys $319[46,47]$ and $\alpha$ His320 [48]; these observations were interpreted with the assumption of a role of a general acid for $\alpha \mathrm{Cys} 319$, consistently with the Australian hypothesis [4], and of a general base for $\alpha$ His 320 , having a $\mathrm{p} K_{\mathrm{a}}$ around 6.5 and thus being deprotonated at the optimal $\mathrm{pH}$ for catalysis (7.5-8.0). The latter residue was thus proposed to activate a nickel-bound water molecule, yielding the hydroxide ion responsible for the nucleophilic attack on urea during catalysis [48].

\section{The crystal structures and the American mechanisms (1995-1997)}

In 1995 the first two X-ray crystal structures of native urease were reported from the bacterium Klebsiella aerogenes, one with the PDB code $1 \mathrm{KAU}$, and the other with the PDB code 2KAU (Fig. 2a,b) [32]. In both cases, KAU was shown to oligomerize as a trimer of trimers in a $(\alpha \beta \gamma)_{3}$ triangular arrangement (Fig. 1). In the structures, three active sites were identified, located in each $\alpha$ subunit and containing two closely spaced $\mathrm{Ni}$ atoms [defined as $\mathrm{Ni}(1)$ and $\mathrm{Ni}(2)$ ] separated by $3.5 \AA$, in accordance with previous spectroscopic results [44] (Fig. 2). The presence of a carbamylated lysine residue, indicated as $\alpha$ Lys $217^{*}$, bridging the two Ni atoms using its $\mathrm{O} \theta 1$ and $\mathrm{O} \theta 2$ atoms, was observed, consistently with carbon dioxide requirement for the in vitro activation of urease [49]. Other common features for the two structures were the coordination of $\mathrm{Ni}(1)$ to $\alpha \mathrm{His} 246 \mathrm{~N} \delta$, $\alpha \mathrm{His} 272 \mathrm{~N} \varepsilon$, and the $\mathrm{O} \theta 1$ atom of $\alpha \mathrm{Lys} 217^{*}$, and the binding of $\alpha$ His $134 \mathrm{~N} \varepsilon, \alpha \mathrm{His} 136 \mathrm{~N} \varepsilon, \alpha \mathrm{Asp} 360 \mathrm{O} \delta 1$, and the O 02 atom of $\alpha$ Lys $217 *$ to $\mathrm{Ni}(2)$ (Fig. 2). In both structures, Ni(1) resulted in an unprecedented three-coordinated geometry. In the 1KAU structure, a water molecule (indicated as Wat-1) was reported to bind $\mathrm{Ni}(2)$ to complete a distorted bipyramidal penta-coordination geometry (Fig. 2a). The authors further affirmed that, in addition to Wat-1, a water molecule weakly binds $\mathrm{Ni}(1)$, thus completing a pseudo-tetrahedral coordination geometry; however, this water molecule was not refined in the model and it is not present in the structure deposited in the PDB. Additionally, a suggestion was made that Wat-1, even though refined at full occupancy as a terminal ligand to $\mathrm{Ni}(2)$, could also be moving onto two 
Fig. 2 Model structures of the active site of $K$. aerogenes urease (KAU) as evolved from the initial X-ray diffraction data (a PDB code $1 \mathrm{KAU}$; b PDB code $2 \mathrm{KAU}$ ) to the more recent interpretation (c PDB code $1 \mathrm{FWJ}$ ). d Displays the ribbon diagram of the active site of KAU, highlighting the mobile flap in the closed conformation depicted according to the B-factor, thus showing the large mobility in this key feature of urease

additional positions, either as terminal ligand for $\mathrm{Ni}(1)$ or as bridging the two $\mathrm{Ni}$ atoms [32]. On the other hand, no nickel-bound water molecule is found in the $2 \mathrm{KAU}$ refined model structure, which thus features a tetra-coordinated $\mathrm{Ni}(2)$ with an atypical geometric arrangement (Fig. 2b). In the paper, however, the authors stated that, in the case of the X-ray diffraction dataset that eventually yielded $2 \mathrm{KAU}$, excess electron density was detected, having the appropriate size for a urea molecule or a bicarbonate ion, but it was not refined into a model [32].

The coordination geometries that emerged from these first two crystal structures were not, in any case, consistent with the previous XAS studies reported by the same group on KAU, which were interpreted with the presence of two penta-coordinated $\mathrm{Ni}(\mathrm{II})$ ions [44]. These inconsistencies were partially resolved later on, when a new crystal structure of KAU was made available by the same authors (PDB code $1 \mathrm{FWJ}$ [50]. In that study, the electron density around the $\mathrm{Ni}$ (II) ions was interpreted as due to the presence of three water molecules: $\mathrm{W}(1)$ bound to $\mathrm{Ni}(1), \mathrm{W}(2)$ bound to $\mathrm{Ni}(2)$ and $\mathrm{W}(\mathrm{B})$ in a nickel-bridging position (Fig. 2c). However, the $\mathrm{O} \cdots \mathrm{O}$ distances between these three $\mathrm{Ni}$-bound water molecules (2.0-2.5 $\mathrm{\AA}$ ) were considered too short to allow them to be simultaneously present, and were refined with variable occupancy $[0.79,1.25$ and 0.90 for $\mathrm{W}(1), \mathrm{W}(2)$ and $\mathrm{W}(\mathrm{B})$, respectively]. In this way, $\mathrm{Ni}(1)$ appeared to be penta-coordinated in a distorted square-pyramidal geometry, while $\mathrm{Ni}(2)$ was hexa-coordinated in a pseudo-octahedral ligand environment, in agreement with all previous spectroscopic observations [50]. However, the authors stated that "the high occupancy of these three water positions that can only be partially occupied suggests that this interpretation is not the complete story" [50]. This was a critical point, as the solvation state of the active site of this hydrolytic enzyme is a key information required to understand its mechanism.

The active site of KAU was found in a pocket enclosed by $\alpha$ Ala167, $\alpha$ His219, $\alpha$ Glu220, $\alpha$ Asp221, $\alpha$ Gly277, $\alpha$ Cys319, $\alpha$ His320, $\alpha$ Arg336, $\alpha$ Ala363, and $\alpha$ Met364. Residues $\alpha$ Cys 319 and $\alpha$ His320 were also found to be part of a 30-residues helix-turn-helix (from residues 310 to 339) covering the active site cavity, that was described as highly mobile and suggested to change its conformation from a closed state, as found in the $1 \mathrm{KAU}, 2 \mathrm{KAU}$ and $1 \mathrm{FWJ}$, to an open state (not observed) in order to allow urea extensive access to the active site (Fig. 2d) [32].
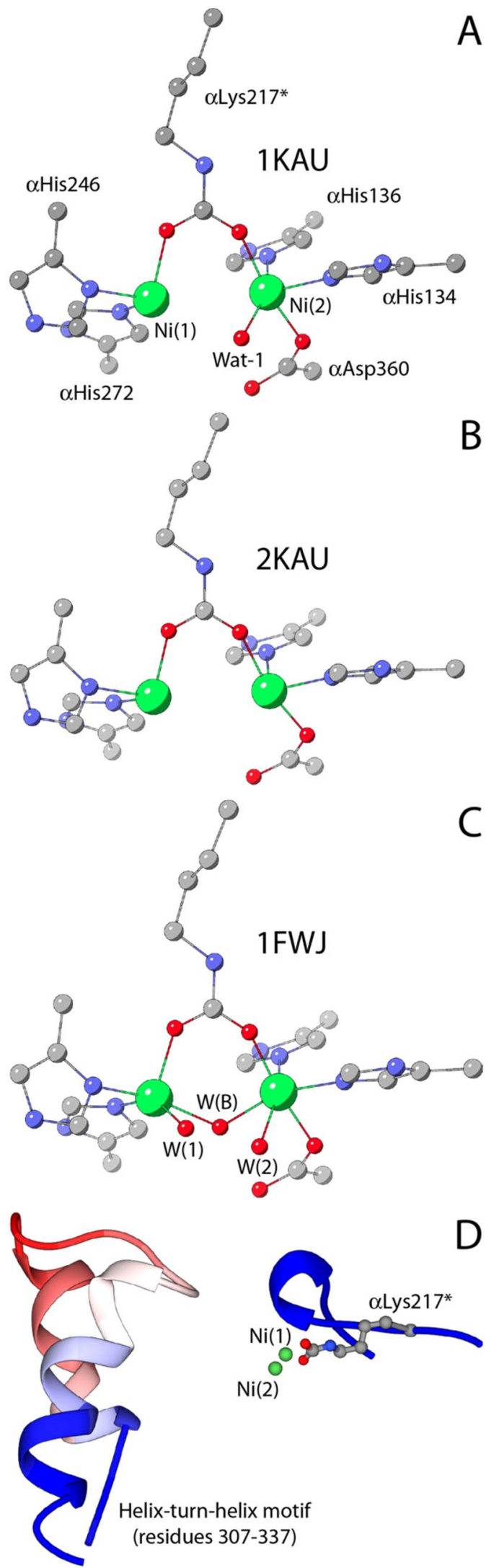

B

A

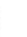

D

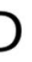


Guided by the structural information on KAU, Hausinger et al. proposed a mechanism that involved different roles for the two $\mathrm{Ni}(\mathrm{II})$ ions [32]. In the first step of this hypothesis, urea would bind in a mono-dentate mode in the active site of urease by coordinating to the least coordinatively saturated $\mathrm{Ni}(1)$ via its carbonyl oxygen atom, completing a tetracoordination environment for this ion and causing polarization of the carbonyl group, consistently with the Australian mechanism [4]. The structure of KAU further suggested that this interaction is aided by $\alpha \mathrm{His} 219 \mathrm{~N} \varepsilon \mathrm{H}$ acting as a $\mathrm{H}$-bonding donor to the urea $\mathrm{O}$ atom, corroborating previous functional studies [48], and that the carboxylic groups in the side chains of $\alpha \mathrm{Glu} 220, \alpha \mathrm{Asp} 221$ and the $\mathrm{Ni}(2)$-binding $\alpha \mathrm{Asp} 360$, as well as the backbone carbonyl $\mathrm{O}$ atoms of $\alpha$ Ala167, $\alpha$ Gly277 and $\alpha$ Ala363 could favor the binding of urea by providing $\mathrm{H}$-bond acceptors for the substrate amide group (Scheme 4) [32].

In the second step, a hydroxide ion, identified as the Wat-1 solvent molecule bound to $\mathrm{Ni}(2)$ in the $1 \mathrm{KAU}$ structure, was proposed to act as the nucleophile for the reaction by attacking the carbonyl $\mathrm{C}$ atom of urea with the formation of a tetrahedral intermediate (Scheme 4). In the final step, the tetrahedral intermediate was assumed to decompose, with the participation of an unidentified generic acid that was previously proposed to protonate a $\mathrm{C}_{\text {urea }}-\mathrm{NH}_{2}$ group [51]. This mechanism modified the previously suggested roles for $\alpha$ Cys319 and $\alpha$ His320 [46-48]. In particular, the structure of KAU excluded the possibility for $\alpha \mathrm{Cys} 319$, preliminary classified as the general acid [46,47], to carry out this role because it is too far from the position of the urea amide group that needs to be protonated, and was instead implied in assisting the correct orientation of the adjacent $\alpha$ His320 residue by steric effects [32]. On the same basis, the structure of KAU excluded that $\alpha$ His 320 could act as the catalytic base needed to generate the nucleophilic hydroxide, as initially hypothesized [48], because of the large distance from Wat-1 [32]. The action of a general base was instead suggested, on the basis of the KAU structure, to be carried out by the Ni(2)-bound $\alpha$ Asp360 O 81 atom [32].

The new structural framework for KAU, obtained in 1997 and involving three solvent molecules around the dinickel cluster [50], suggested a further modification to the initial hypothesis depicted in Scheme $4[29,50]$. According to this revised mechanism, urea would bind $\mathrm{Ni}(1)$ with its carbonyl $\mathrm{O}$ atom, an interaction stabilized by H-bonds not only involving $\alpha \mathrm{His} 219 \mathrm{~N} \varepsilon \mathrm{H}$ as initially suggested, but also comprising four additional $\mathrm{H}$-bonds between the amide hydrogens of urea and $\alpha$ Gly277, $\alpha$ Ala363, $\alpha$ Ala167 carbonyl $\mathrm{O}$ atoms as well as, possibly, $\alpha \mathrm{Cys} 319 \mathrm{~S} \gamma$ acting as an H-bond acceptor (Scheme 5). Similar to their first proposal, in this revised mechanism Hausinger et al. suggested that the subsequent step would be the nucleophilic attack by the hydroxide form of the $\mathrm{Ni}(2)$-bound water molecule onto the urea $\mathrm{C}$ atom, to form a tetrahedral hydrated urea intermediate. The latter would witness a large increase in the basicity of the amide $\mathrm{N}$ atoms, facilitating the subsequent transfer of a proton from the protonated form of the side chain imidazole of $\alpha \mathrm{His} 320$, in a step that would occur concomitantly or after the nucleophilic attack. As in the first proposed mechanistic model, the protonated tetrahedral intermediate would quickly collapse upon formation of the $\mathrm{C}_{\text {urea }} \mathrm{NH}_{3}{ }^{+}$group to yield ammonia and carbamate, which would subsequently escape from the active site restoring the enzyme native form in a non-ratelimiting step.

The substantial modification proposed for the role of $\alpha$ His320 with respect to the previous hypothesis, assumed that this residue undertakes a dual role in (i) aiding the maintenance of a correct active site geometry that allows productive urea binding, and (ii) acting as a general acid able to produce a good leaving group during urea breakdown. This hypothesis was inconsistent with previous observation by the same group that suggested that $\alpha \mathrm{His} 320$ is deprotonated at the optimal $\mathrm{pH}$ for catalysis (7.5-8.0) [48]. Indeed, to function as a general acid, $\alpha$ His 320 should be protonated, which raised the dilemma of how an enzyme with a $\mathrm{pH}$ optimum near 8 could require the protonated form of a group with $\mathrm{p} K_{\mathrm{a}}$ near 6.5. This conundrum was explained using the so-called "reverse protonation hypothesis" [52, 53], by which the bellshaped $\mathrm{pH}$ profile of urease would result from a low- $\mathrm{p} K_{\mathrm{a}}$ group that must be protonated, and a high-p $K_{\mathrm{a}}$ group that must be deprotonated, at the $\mathrm{pH}$ optimum. For urease, this would mean that $\alpha \mathrm{His} 320$ must be protonated for catalysis and another group with a $K_{\mathrm{a}}$ near 9 must be deprotonated. The authors also speculated that the high- $\mathrm{p} K_{\mathrm{a}}$ group could be W(2) itself, because such a $K_{\mathrm{a}}$ appeared to be reasonable for a $\mathrm{Ni}(\mathrm{II})$-bound water $[54,55]$, simplifying the model by ruling out the necessity of a general base able to turn W(2) into a hydroxide ion.

Based on this mechanistic hypothesis, additional considerations were made that concerned the 30-residue, highly mobile, helix-turn-helix motif covering the active site cavity and suggested to regulate substrate access by changing its conformation from a closed to an open state [29, 32]. This hypothesis was necessary not only in order to position $\alpha$ His320 for proton transfer to the urea amide $\mathrm{N}$, but also to explain enzyme inhibition by chemicals targeting $\alpha$ Cys 319 [46] as a simple physical effect, namely by not allowing the flap to close properly. However, the open conformation of the KAU mobile flap in the native enzyme remained elusive, with the exception of the structure of the Cys-to-Tyr mutant in which the flap was considered to stay open by steric hindrance [50]. 


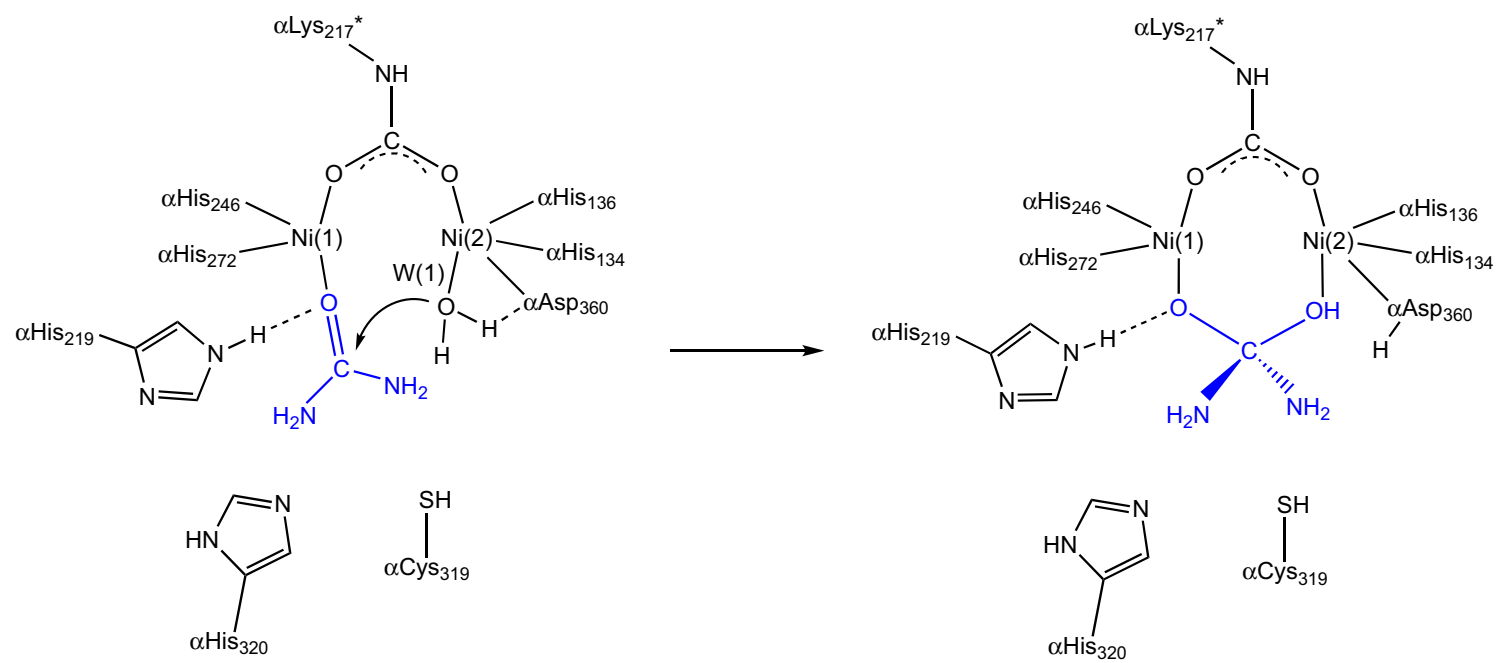

Scheme 4. First proposal for the urease reaction mechanism by Hausinger et al. [32]

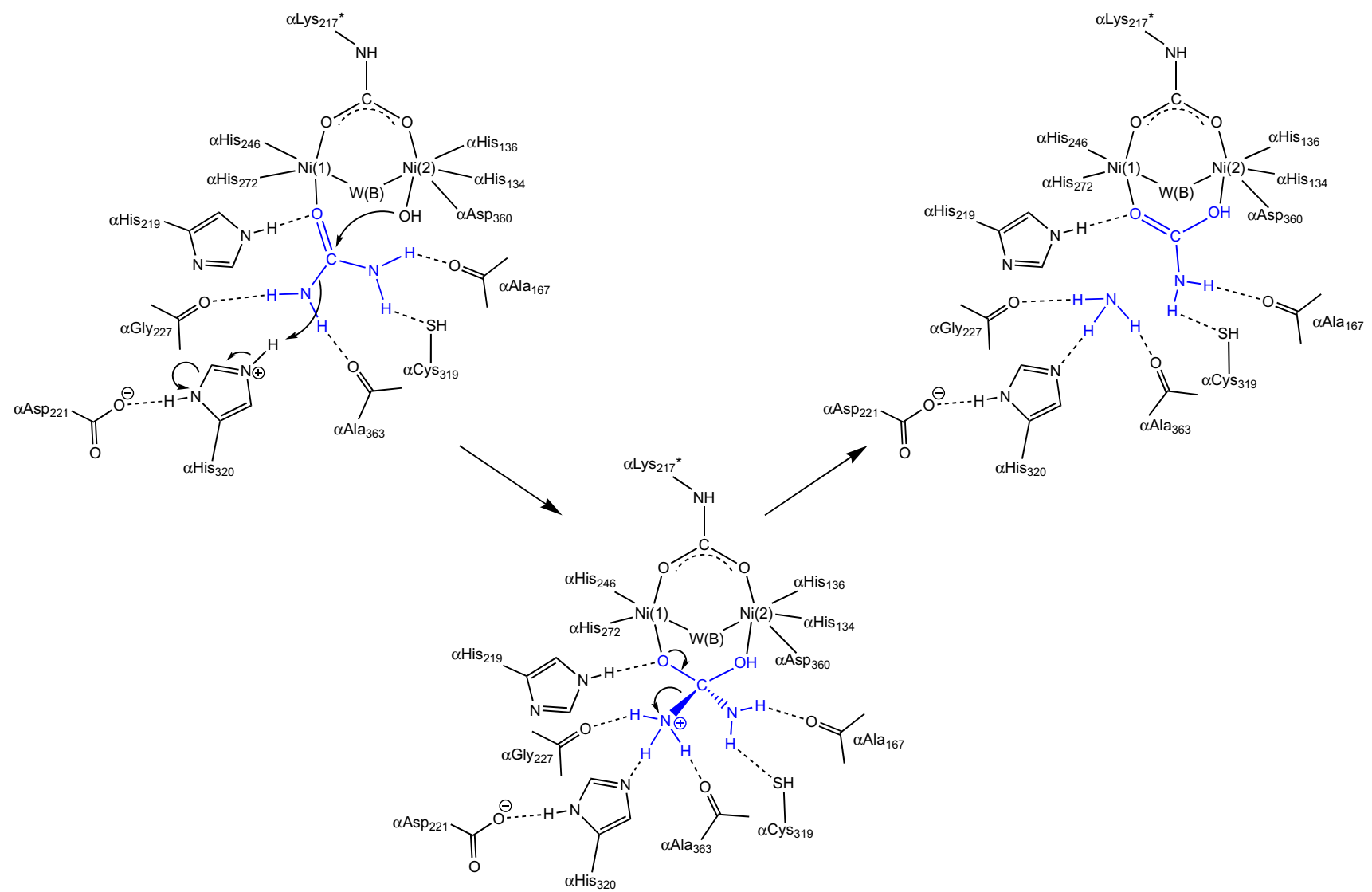

Scheme 5. Second proposal for the urease reaction mechanism by Hausinger et al. [29, 50] 

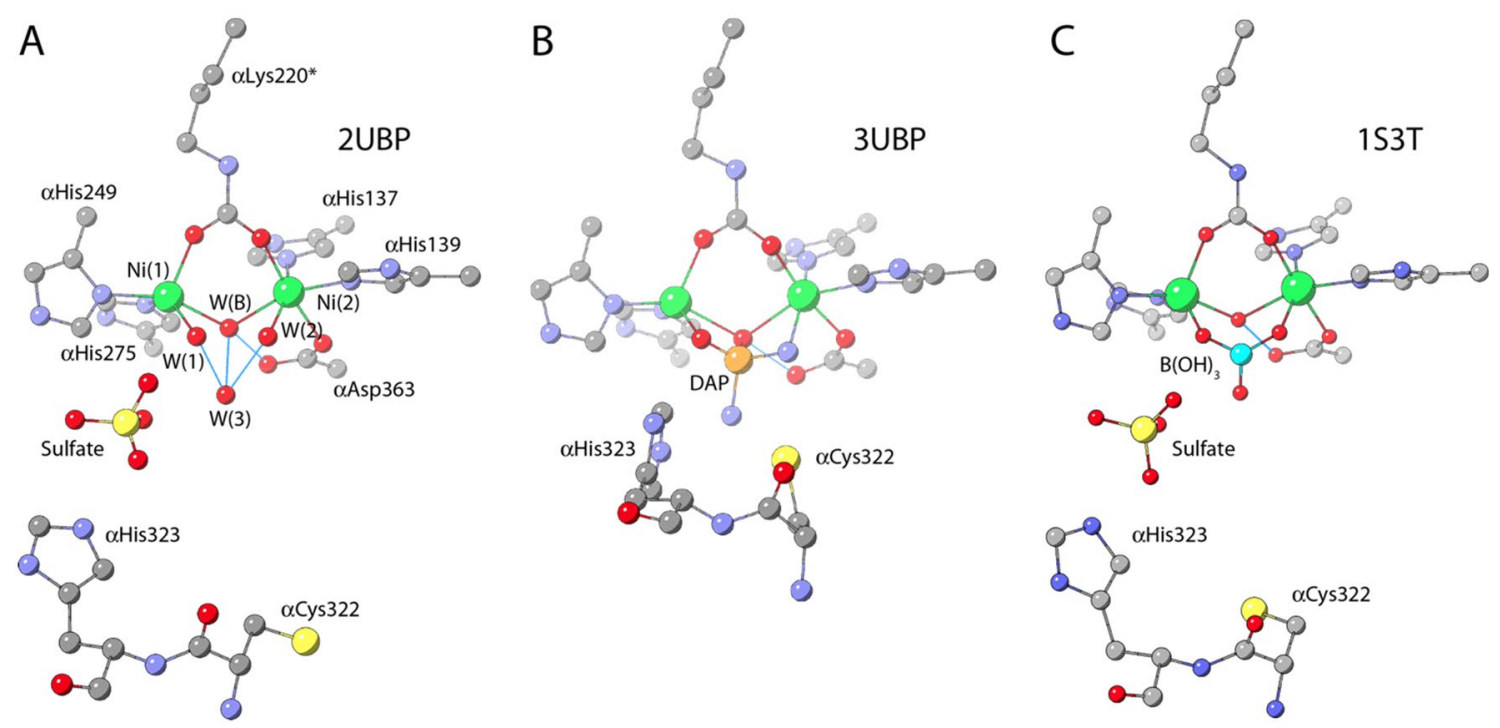

Fig. 3 Model structures of the active site of S. pasteurii urease (SPU) as derived from X-ray diffraction data in the native state (a PDB code 2UBP), bound to diamidophosphate, DAP (b PDB code 3UBP) and to boric acid (c PDB code 1S3T)

\section{The crystal structure of urease-inhibitor complexes and the European mechanism (1999-2004)}

Shortly after the structural characterization of KAU, in 1999 the crystal structure of Sporosarcina pasteurii (formerly known as Bacillus pasteurii) urease (SPU) [33] was determined (PDB code 2UBP). The overall tertiary and quaternary structures of SPU were found to be very similar to that of KAU (Fig. 1). The coordination environment of the $\mathrm{Ni}(\mathrm{II})$ ions in the active site of SPU was also largely comparable to that of KAU (Fig. 3a). In particular, the two Ni(II) ions are separated by $3.7 \AA$ and bridged by the $\mathrm{O} \theta 1$ and $\mathrm{O} \theta 2$ atoms of a carbamylated $\alpha$ Lys $220 *$ (SPU numbering), ${ }^{1}$ $\mathrm{Ni}(1)$ is additionally bound to $\alpha \mathrm{His} 249 \mathrm{~N} \delta$ and $\alpha \mathrm{His} 275 \mathrm{~N} \varepsilon$, while $\mathrm{Ni}(2)$ is bound to $\alpha \mathrm{His} 137 \mathrm{~N} \delta$, to $\alpha \mathrm{His} 139 \mathrm{~N} \varepsilon$, and to $\alpha$ Asp363 O81. The hydration environment of the active site of SPU was clearly described with four well-ordered solvent molecules, $\mathrm{W}(1), \mathrm{W}(2), \mathrm{W}(3)$, and $\mathrm{W}(\mathrm{B})$ : the latter symmetrically bridges the two nickel ions, whereas $\mathrm{W}(1)$ and $\mathrm{W}(2)$ complete a distorted square-pyramidal and a distorted octahedral coordination for $\mathrm{Ni}(1)$ and $\mathrm{Ni}(2)$, respectively. The fourth water molecule, $\mathrm{W}(3)$ in a distal position, is at H-bonding distance from $\mathrm{W}(\mathrm{B}), \mathrm{W}(1)$ and $\mathrm{W}(2)$. The authors also assigned the protonation state of $\mathrm{W}(1)$ and $\mathrm{W}(2)$ as neutral water molecules, while $\mathrm{W}(\mathrm{B})$ was considered to be a hydroxide ion according to the estimated $\mathrm{p} K_{\mathrm{a}}$ values

\footnotetext{
${ }^{1}$ In general, the numbering of the amino acid sequence of SPU $\alpha$ subunit in the surroundings of the active site corresponds to that of $\mathrm{KAU}+3$.
}

for a water molecule bound to the $\mathrm{Ni}(\mathrm{II})$ hexa-aquo ion ( $\mathrm{p} K_{\mathrm{a}}$ around 10.6) and for water-bridged bimetallic complexes (having a very acidic $\mathrm{p} K_{\mathrm{a} 1}$ and a $\mathrm{p} K_{\mathrm{a} 2}$ slightly lower than the $\mathrm{p} K_{\mathrm{a}}$ of the first ionization of a single ion bound to water) [54]. In this context, the third lone pair of the W(B) hydroxide, not involved in Ni-coordination, was considered to be involved in a H-bond with $\alpha$ Asp363 O82. The H-bonding network of the three Ni-bound water molecules is completed by $\mathrm{W}(1)$ receiving a $\mathrm{H}$-bond from $\alpha \mathrm{His} 222 \mathrm{~N} \varepsilon$, which is, as in KAU, protonated as deduced from the interaction of $\alpha \mathrm{His} 222 \mathrm{~N} \delta$ with the peptide NH group of $\alpha \mathrm{Asp} 224$, whereas $\mathrm{W}(2)$ forms a strong hydrogen bond with $\alpha$ Ala170 $\mathrm{O}$, which acts as $\mathrm{H}$-bonding acceptor.

In the case of SPU, the authors provided a rationale for the existence of this pseudo-tetrahedral arrangement of closedspaced solvent molecules $(\mathrm{O} \cdots \mathrm{O}$ distances in the $2.1-2.4 \AA$ range) around the di-nickel cluster [33], suggesting the presence of a four-centered hydrogen-bonding network involving a proton located in the center of the tetrahedron constituted by $\mathrm{W}(1), \mathrm{W}(2), \mathrm{W}(3)$ and $\mathrm{W}(\mathrm{B})$ and assisted by residues acting as $\mathrm{H}$-bonding donors and acceptors ( $\alpha$ Asp363 O 2 , $\alpha \mathrm{His} 222 \mathrm{~N} \varepsilon$, and $\alpha$ Ala170 O). In addition, the presence of a sulfate ion close to the di-metallic Ni cluster (Fig. 3a) was proposed to additionally stabilize $\mathrm{W}(3)$ : this anion forms a hydrogen bond with $\alpha \mathrm{His} 323 \mathrm{~N} \varepsilon$ and is located between the four-water/hydroxide cluster and the nearby $\alpha \operatorname{Arg} 339$, forming a strong salt bridge. While the presence of sulfate in crystals of native SPU is probably due to its high concentration in the crystallization buffer, in native KAU, also obtained from sulfate-rich solutions, its position is occupied by the imidazole ring of $\alpha \mathrm{His} 320$ ( $\alpha \mathrm{His} 323$ according to SPU numbering) and none of the published KAU structures 
shows sulfate binding $[29,32,50]$. W(3) is also at the center of additional possible multiple H-bonding interactions with $\alpha$ Asp363 O82 and $\alpha$ Gly280. In addition to the H-bonding network thus described that can rationalize the short $\mathrm{O} \cdots \mathrm{O}$ distances found in the tetrahedral solvent cluster in the active site of SPU, a detailed analysis of the interactions between $\mathrm{W}(1)$ or $\mathrm{W}(2)$ and the amino acids facing the active-site cavity revealed the presence of close van der Waals contacts between W(1) and $\alpha \mathrm{His} 249 \mathrm{C} \varepsilon$, $\alpha \mathrm{His} 249 \mathrm{~N} \delta, \alpha \mathrm{Gly} 280 \mathrm{O}$, and $\alpha$ Lys220* O 01 , and between W(2) and $\alpha$ His139 C $\varepsilon$, $\alpha$ His $139 \mathrm{~N} \varepsilon$, $\alpha$ Ala366 C $\beta$ and $\alpha$ Lys220* O 2 , which were also used to rationalize the existence of this water "droplet" in the active site of SPU [33]. The structure of native SPU was an unprecedented example of a native urease structure showing the mobile flap covering the active site in the elusive open conformation.

Concomitantly with the crystal structure of native SPU, Benini et al. also determined the crystal structure of SPU bound to diamidophosphate (DAP), a molecule resulting from the enzymatic hydrolysis of phenylphosphodiamidate (PPD) and considered to behave like an analog of the transition state or the intermediate of the urea hydrolysis reaction [33]. In that structure (PDB code 3UBP), the tetrahedral molecule of DAP exactly replaces the cluster of four solvent molecules found in native SPU, binding to $\mathrm{Ni}(1)$ and to $\mathrm{Ni}(2)$ with one $\mathrm{O}$ and one $\mathrm{N}$ atom, respectively, with the second $\mathrm{O}$ atom bridging the two $\mathrm{Ni}$ atoms and the second $\mathrm{N}$ atom pointing towards the active site cavity (Fig. $3 \mathrm{~b}$ ). A hydrogen-bonding network similar to that found in the native form of the enzyme stabilizes the ligand in the active site, with the $\mathrm{Ni}(1)$-bound DAP $\mathrm{O}$ atom receiving a $\mathrm{H}$-bond from the protonated $\alpha \mathrm{His} 222 \mathrm{~N} \varepsilon$, the $\mathrm{Ni}(2)$-bound DAP $\mathrm{N}$ atom donating two hydrogen bonds to the backbone carbonyl $\mathrm{O}$ atoms of $\alpha$ Ala170 and $\alpha$ Ala366, and the Ni-bridging DAP O atom being at $\mathrm{H}$-bonding distance to $\alpha \mathrm{Asp} 363$ O82, implying the presence of a proton on the bridging DAP $\mathrm{O}$ atom. Finally, the distal DAP N atom donates a bifurcated H-bond to the $\alpha$ Ala366 backbone $\mathrm{O}$ atom and to $\mathrm{N} \varepsilon$ atom of the mobile-flap $\alpha$ His 323 residue. The position of $\alpha$ Cys 322 and $\alpha$ His 323 was significantly shifted as compared to the resting state as a consequence of a large change occurring in the helix-turn-helix region (Fig. 3a, b) that adopts a closed conformation. In this way it was experimentally proven, for the first time, that the urease active site flap could assume two different states-open, as in native SPU, or closed, as in the DAP-inhibited SPU [33] and in all previous native KAU structures, strongly supporting the hypothesis previously suggested by Hausinger et al. that this conformational change is important for the urease mechanism [29].

Inspired by their findings, Benini et al. proposed an alternative reaction pathway, illustrated in Scheme 6 and referred here as the "bridging hydroxide mechanism" [33, 56]. According to this hypothesis, urea would enter the active site cavity when the flap is in the open conformation, replacing $\mathrm{W}(1), \mathrm{W}(2)$, and $\mathrm{W}(3)$, with $\alpha$ His 222 being involved, as previously demonstrated, in a hydrogen-bonding network that orientates the substrate in the catalytic cavity and stabilizes the initial binding of the carbonyl oxygen to the more electrophilic five-coordinated $\mathrm{Ni}(1)$. In this binding mode, one of its amide groups would move close to the six-coordinated $\mathrm{Ni}(2)$ and eventually binds, chelating the two metal ions. In the bidentate nickel-binding mode of urea, both $\mathrm{Ni}$ (II) ions would have a direct role in substrate binding and activation. This binding mode would be further stabilized by a rearrangement of $\alpha$ Ala366 backbone, which tilts its carbonyl $\mathrm{O}$ atom towards $\mathrm{Ni}(2)$ and, together with the carbonyl group of $\alpha$ Ala170, acting as hydrogen-bond acceptors with the urea $\mathrm{NH}_{2}$ group. The latter two residues, $\alpha$ Ala170 and $\alpha$ Ala366, would also assist urea binding to $\mathrm{Ni}(2)$ by enhancing the Lewis basicity of the amide group of urea. The orientation of the substrate would be further induced by the asymmetric structural features of the activesite residues, positioned to act as hydrogen-bond donors in the vicinity of $\mathrm{Ni}(1)$ and as hydrogen-bond acceptors in the vicinity of $\mathrm{Ni}(2)$. These results suggested an enzyme active site specifically designed to selectively bind the substrate in an orientation-specific mode.

Altogether, these interactions polarize the $\mathrm{C}-\mathrm{O}$ and the $\mathrm{C}-\mathrm{NH}_{2}$ bonds, bringing the $\mathrm{C}$ atom of urea in close proximity to the nickel-bridging hydroxide. In this hypothesis, the latter anion would be the nucleophile that attacks the carbonyl $\mathrm{C}$ of urea, forming a tetrahedral transition state. At this stage, a conformational change of the flap from an open to a closed state would ensue. In this scenario, $\alpha$ His 323 in its neutral form would move ca. $5 \AA$ closer to the reaction site and would be in the proper position to form a H-bond between its $\mathrm{N} \varepsilon$ imidazole atom and the distal $-\mathrm{NH}_{2}$ group of the transition state/intermediate of the reaction. At this stage, the proton needed to generate a nascent ammonia molecule through the cleavage of a $\mathrm{C}-\mathrm{NH}_{3}{ }^{+}$bond could be provided by the bridging hydroxide itself, which is now part of a diamino-(hydroxy)methanolate moiety, and therefore very acidic after the formation of the $\mathrm{C}-\mathrm{O}$ bond. This event was proposed to occur via the nearby carboxylate group of $\alpha$ Asp363, later shown to undergo a dihedral rotation along the $\mathrm{C} \alpha-\mathrm{C} \beta$ bond, approaching alternatively the bridging hydroxide or the distal $\mathrm{NH}_{2}$ group, following the determination of the crystal structure of the SPU complex with the inhibitor acetohydroxamic acid [57]. According to this hypothesis, the release of ammonia from the active site would be assisted by the movement of $\alpha \mathrm{His} 323$ when the mobile flap opens. The resulting negatively charged carbamate is then released, owing to the unfavorable interaction between the deprotonated nickel-bridging carbamate oxygen and $\alpha A s p 363$ O 22 , in a process assisted by the movement of the positively charged $\alpha \operatorname{Arg} 339$ upon flap opening. 


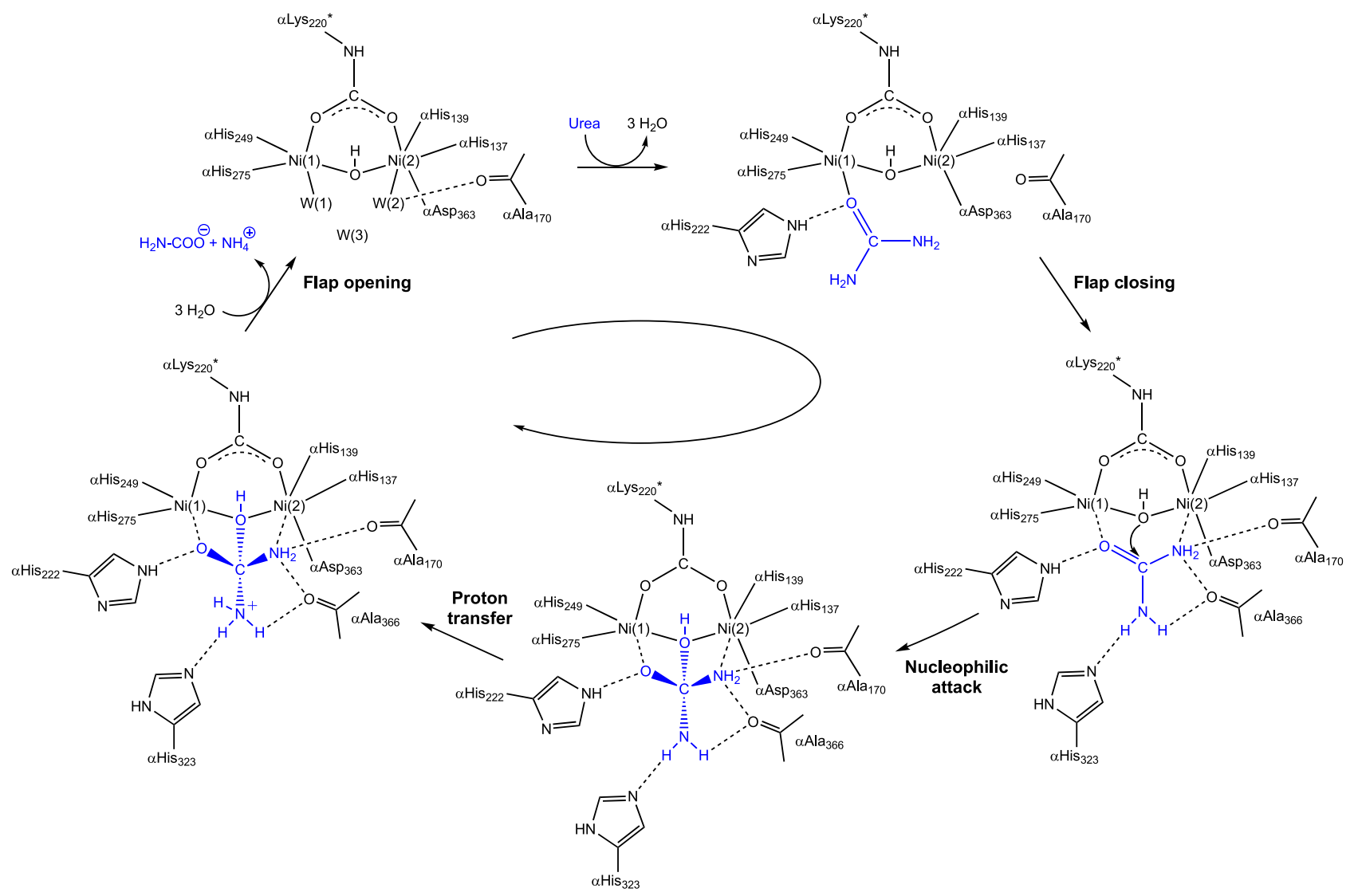

Scheme 6. Urease reaction mechanism proposed by Benini et al. [33]

According to this proposed mechanism, the bridging hydroxide simultaneously acts as the nucleophile and the general acid, while $\alpha$ His 323 acts by stabilizing the positive charge which develops on the transition state rather than deprotonating the hydrolytic water, as proposed by Hausinger and co-workers in their first hypothesis.

The "bridging hydroxide mechanism" raised some initial criticism among the bioinorganic community during the XXXIII ICCC in Florence (August 1998), the 5th ISABC in Corfu (April 1999), and the 9th ICBIC in Minneapolis (August1999), with negative comments based mainly on the supposed kinetic inertia of a doubly coordinated nucleophile [58]. However, shortly after this hypothesis was proposed, two additional studies were reported that seemed to support it. Specifically, one study reported and discussed the crystal structure of the SPU in complex with phosphate (PHO, PDB code 1IE7), a competitive inhibitor [58], and another described a computational approach to the enzyme mechanism [59]. In particular, the latter confirmed the hypothesis that urea must first bind to the enzyme active site with the flap in the open conformation, as the entrance to the active site would be otherwise prevented by steric clashes. Additionally, the calculations supported the initial binding of the carbonyl $\mathrm{O}$ of urea to $\mathrm{Ni}(1)$, displacing $\mathrm{W}(1), \mathrm{W}(2)$ and $\mathrm{W}(3)$ and leaving the bridging hydroxide in place. However, the binding of one of the amido- $\mathrm{NH}_{2}$ groups of urea to $\mathrm{Ni}(2)$ was proven not to be favored unless the flap moves into a closed conformation, a phenomenon that decreases the active site volume, forcing this interaction to take place [59]. Closure of the flap would also be responsible for the stabilization of the catalytic transition state through the formation of multiple $\mathrm{H}$-bonds with the active site residues $\alpha$ Ala170 and $\alpha$ Ala366, as initially proposed. These interactions would induce a change of this $\mathrm{N}$ atom from a "pseudo" $\mathrm{sp}^{2}$ hybridization, with some $\mathrm{sp}^{3}$ character, to a pure $\mathrm{sp}^{3}$ hybrid, thus favoring its coordination to $\mathrm{Ni}(2)$, which would compensate the loss of resonance delocalization energy of the urea molecule [59]. The same calculations suggested that the nucleophilic attack of the bridging hydroxide occurs concomitantly with the formation of the coordination bond between the urea $-\mathrm{NH}_{2}$ group and $\mathrm{Ni}(2)$ [59], instead of following it, as originally proposed $[33,56]$.

In 2004, the determination of the crystal structure of SPU bound to boric acid, $\mathrm{B}(\mathrm{OH})_{3}$, considered to behave like a substrate analog [60], reinforced the bridging hydroxide mechanism (PDB code $1 \mathrm{~S} 3 \mathrm{~T}$ ). In the SPU-B $(\mathrm{OH})_{3}$ complex, the urea-like inhibitor replaces $\mathrm{W}(1), \mathrm{W}(2)$ and $\mathrm{W}(3)$ by symmetrically coordinating the $\mathrm{Ni}(\mathrm{II})$ ions with two oxygen 
atoms, while the third $\mathrm{O}$ atom points toward the cavity opening, not perturbing the position of the bridging hydroxide (WB). In this structure, the H-bond network around the boric acid $\mathrm{O}$ atoms resembles that of the water molecules in the native urease (Fig. 3c). The structure revealed that the bridging hydroxide is placed almost perpendicular to the plane of the $\mathrm{B}(\mathrm{OH})_{3}$ molecule, with a $\mathrm{B} \cdots \mathrm{OH}$ distance of only $2.1 \AA$. The different reactivity between urea (a substrate) and boric acid (an unreactive substrate analog and an enzyme inhibitor) was ascribed to unfavorable symmetry and energy of the highest energy orbital carrying the two electrons necessary for the bond formation (the HOMO) on the bridging hydroxide nucleophile and the lowest energy empty orbital (the LUMO) on the inhibitor.

\section{And yet it moves: the role of the active site flap (1995-2019)}

The helix-turn-helix motif covering the active site cavity carries, at the tip of the mobile turn region between the two helices, the fully conserved $\alpha$ His $320 / \alpha H i s 323$ residue (KAU/SPU numbering), which has been, in the differently proposed mechanisms described above, assumed to act as a general acid or a general base, but in any case, involved in key catalytic proton transfer steps. The ability of this motif to move, initially suggested by Hausinger et al. for KAU $[29,32]$ was proven for SPU by comparing the structures of native and DAP-inhibited enzyme [33], which additionally revealed that the position of this key residue shifts by ca. $5 \AA$ towards the di-nickel center upon transition of the flap from an open to a closed conformation. The mobile flap was found in the open conformation in the case of native SPU, as well as in the structures of SPU bound to competitive and uncompetitive inhibitors [5, 6, 33, 56-58, 60-68]. In some of these cases the flap is forced to stay open, as for urease inactivated by 1,4-benzoquinone [64], catechol [66], and heavy metal ions such as $\operatorname{Ag}(\mathrm{I})$ [67] and $\mathrm{Au}(\mathrm{I})$ [68], supporting the idea that flap closure is absolutely necessary for catalysis to occur.

The structural and functional information available on ureases from different sources thus provided a strong correlation between the efficiency of the catalytic mechanism of urease and the viability for the existence of at least two different conformations for the mobile flap, open or closed. The critical role of the flap in stabilizing the substrate or the transition state into the active site, was initially based on the fact that the structure of native SPU [33], as well as boric acid-SPU complex (an unreactive substrate analog), showed a flap in the open conformation [60], while the structure of SPU bound to the transition state analog DAP, resulting from the in situ hydrolysis of PPD showed a flap in the closed state [33]. This observation was later confirmed in the case of SPU bound to $N$-mono-amino thiophosphate (MATP, PDB code 5OL4), the latter resulting from the enzymatic hydrolysis of $N$-( $n$-butyl)-thiophosphoric triamide (NBPT), and differing from the structure of the DAP-SPU complex only by substitution of the distal $\mathrm{N}$ atom of DAP with a $\mathrm{S}$ atom in the case of MATP [65]. Altogether, this information reinforced the idea that this structural change is mandatory for urease to stabilize the substrate or the transition state formed upon nucleophilic attack of the bridging hydroxide on urea.

Some reasons for the conformational variability of the mobile flap had been already considered in the early days of urease structural investigations. In particular, two hypotheses were proposed: (i) one by which the extended interactions involved in flap closure favor the open or disordered conformation, so that only favorable interactions caused by the presence of urea in the active site are required to close the flap, and (ii) another that implied that the extended interactions made by the flap are sufficient to favor flap closure, but side chains and water in the urea binding pocket make unfavorable interactions that destabilize the closed state of the empty enzyme [29]. The authors favored the second explanation, considered to be more consistent with the view that the enzyme is designed for maximally effective binding of the transition state [29].

An alternative explanation for the differences between the case of KAU (flap mainly closed) and SPU (flap mainly open) has been recently provided by kinetic and crystallographic studies carried out on SPU inhibited by $N$-( $n$-butyl)phosphoric triamide (NBPTO) and yielding DAP-SPU complexes $[69,70]$. This rationalization, based on the working hypothesis that the different $\mathrm{pH}$ reported for the crystallization of KAU $(\mathrm{pH}>7)$ and SPU $(\mathrm{pH}<7)$ is the source of these dissimilarities, was experimentally challenged by determining the structure of SPU inhibited in the presence of NBPTO and bound to DAP at $\mathrm{pH} 7.5,7.0$ and 6.5 (PDB codes 6RKG, 6H8J and 6RP1, respectively) [69, 70]. The DAP ligand was shown, by ${ }^{31} \mathrm{P}$ NMR, not to change protonation state in this $\mathrm{pH}$ range [70]. The result of this analysis showed that the stabilization of the flap in an open/closed state is indeed dictated by $\mathrm{pH}$, promoting an open conformation at more acidic-to-neutral pH (Fig. 4a), and a closed conformation at neutral-to-alkaline pH (Fig. 4b) [69, 70]. In particular, a combination of kinetic and structural studies showed that $\alpha$ His 323 in SPU has a $K_{\mathrm{a}}$ of ca. 6.6 , so that at higher $\mathrm{pH}$ values a large percentage of the protein has the flap in the closed conformation and the imidazole group of this residue is deprotonated and found inserted in the active site cleft, forming two hydrogen bonds with $\alpha$ Asp224 O 22 , using the $\mathrm{N} \delta$ atom, and $\alpha \operatorname{Arg} 339 \mathrm{~N} \delta 2$, using the $\mathrm{N} \delta$ atom (Fig. 4b) [69, 70]. The chemical nature of the carboxylic oxygen of $\alpha A$ sp224 as a H-bond acceptor, together with the one of the guanidinium nitrogen of $\alpha \operatorname{Arg} 339$ as a H-bond 
donor, suggested that $\alpha \mathrm{His} 323$ is actually protonated at its $\mathrm{N} \delta$ and deprotonated at its $\mathrm{N} \delta$. On the other hand, at $\mathrm{pH}$ values lower than 6.6, the percentage of the protein with the open conformation of the flap progressively increases, with $\alpha$ His 323 gradually moving, on average, farther away from the di-metallic center. In this latter case, the volume of the active site cavity is occupied by a sulfate ion (that is deprotonated at the crystallization $\mathrm{pH}$ ), which makes two hydrogen-bond interactions through two $\mathrm{O}$ atoms with $\alpha \operatorname{Arg} 339 \mathrm{~N} \eta 1$ and $\mathrm{N} \eta 2$, while a third $\mathrm{O}$ atom is placed at $2.2 \AA$ from $\alpha$ His $323 \mathrm{~N} \varepsilon$, indicating that the latter, must be protonated. Overall, this analysis indicated that, whereas $\alpha \mathrm{His} 323$ is neutral and protonated only at its $\mathrm{N} \delta$ position at the optimum $\mathrm{pH} 7.5$, the same residue is cationic and doubly protonated at $\mathrm{pH}$ 6.5. The importance of the conserved residues $\alpha$ Asp224, $\alpha H i s 323$, and $\alpha \operatorname{Arg} 339$ in the correct positioning of the flap during the catalytic process of urease was already suggested by kinetic studies on KAU [71]. In this view, the triad $\alpha$ Asp224- $\alpha$ His 323- $\alpha$ Arg339 forms a three-member lock-and-key system, in which the protonation state of $\alpha$ His 323 dictates the flap movement toward and away from the active site. In particular, at $\mathrm{pH}$ values greater than the $\mathrm{p} K_{\mathrm{a}}$ of $\alpha \mathrm{His} 323, \mathrm{~N} \varepsilon$ would be deprotonated, allowing $\alpha$ His 323 to interact with both $\alpha$ Asp224 and $\alpha \operatorname{Arg} 339$. In this state, the mobile flap would be more stable in the closed conformation. On the other hand, the protonation of $\alpha \mathrm{His} 323 \mathrm{~N} \varepsilon$, an event that must occur at $\mathrm{pH}$ values below its $\mathrm{p} K_{\mathrm{a}}$ of 6.6 , renders this residue unable be clamped between $\alpha A s p 224$ and $\alpha \operatorname{Arg} 339$ because of the positive charge generated on the imidazole ring, which would prevent its interaction with the positively charged side chain of $\alpha \operatorname{Arg} 339$.

\section{The fluoride ion as a new player (2000-2014)}

The hypothesis of the bridging solvent-derived moiety acting as the catalytic nucleophile in the enzymatic hydrolysis of urea gained further support after the publication of kinetic data of fluoride inhibition of KAU [72]. These studies were interpreted by excluding that fluoride replaces either or both solvent molecules terminally bound to $\mathrm{Ni}(1)$ and $\mathrm{Ni}(2)$, this time assumed to be in the neutral $\mathrm{H}_{2} \mathrm{O}$ form [72], thus suggesting that fluoride replaces the Ni-bridging solvent molecule [72]. Additionally, the authors indicated that fluoride inhibition would occur following turnover, alias upon urea binding to $\mathrm{Ni}(1)$ and not before, an event that could weaken the bond between the bridging solvent molecule, assumed to be a neutral $\mathrm{H}_{2} \mathrm{O}$ considering the $\mathrm{pH}$-dependence of fluoride inhibition [72]. These considerations led the authors to conclude that the "bridging hydroxide" hypothesis was consistent with their result, with the caveat that $\alpha$ His 320 would need to be protonated to act as the general acid in the reaction, differently from what had been proposed in
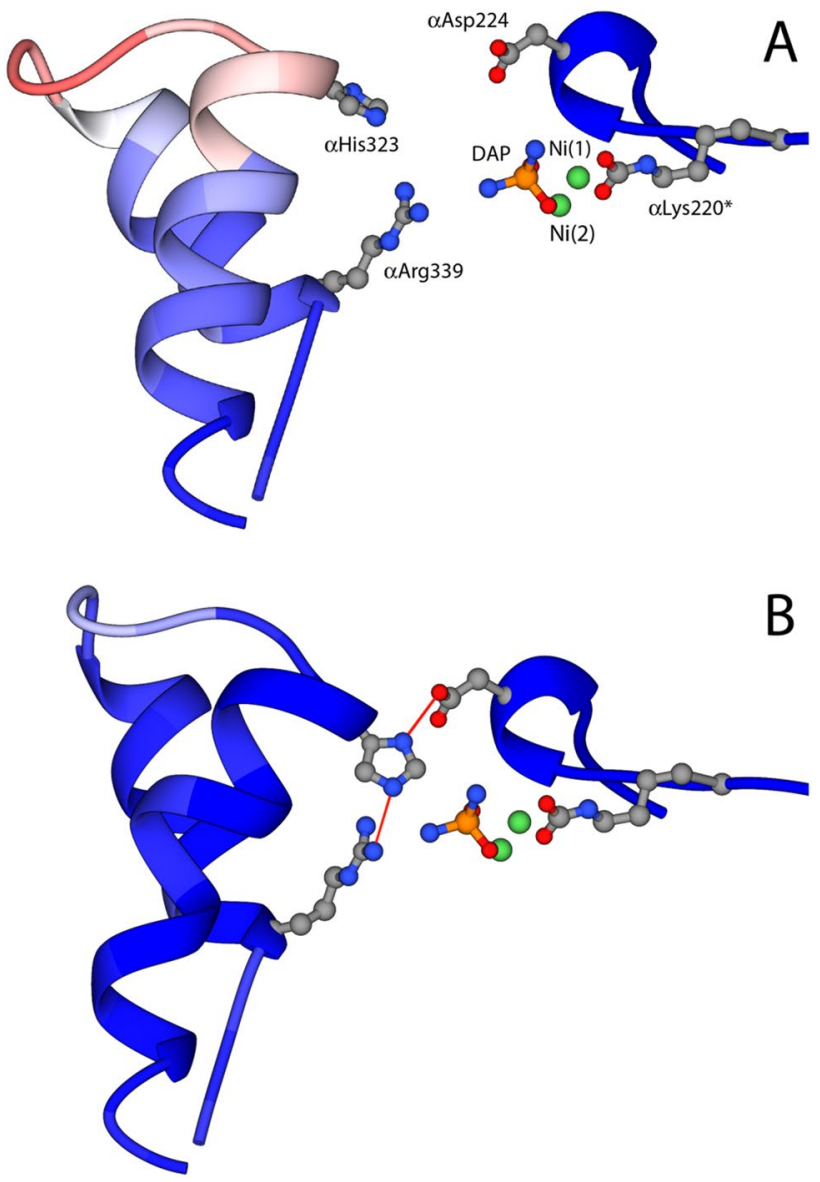

Fig. 4 Ribbon diagram showing the active-site flap of SPU inhibited in the presence of NBPTO and bound to DAP in the open conformation at pH 6.5 (a PDB code 6RP1) and in the closed conformation at pH 7.5 (b PDB code 6RKG). The ribbons are colored according to the crystallographic B-factor. The side chains of $\alpha \mathrm{Lys} 220^{*}, \alpha \mathrm{Cys} 322$, and $\alpha \mathrm{His} 323$ as well as the two $\mathrm{Ni}$ atoms and the bound DAP molecule are also shown

the European mechanism. Shortly after, kinetic studies on KAU mutants of $\alpha$ His 219, $\alpha$ Asp221, $\alpha$ His320 and $\alpha$ Arg336 by the same group were used to support the involvement of the protonated $\alpha \mathrm{His} 320$ as the general acid, and of a bridging solvent molecule as the nucleophile [71]. A variant of this mechanism was also proposed, in which the nucleophile would be the di-anionic oxide ion $\left(\mathrm{O}^{2-}\right)$ and not a hydroxide ion [71].

Additional proof for the "bridging hydroxide" hypothesis was obtained in a study, published in 2014 by Benini and co-workers, reporting a combined kinetic and structural characterization of the inhibition of SPU with fluoride [62]. The study demonstrated that fluoride inhibits SPU with a mixed competitive and uncompetitive mechanism; the latter is predominant and increases with $\mathrm{pH}$ increase, while the latter features an opposite $\mathrm{pH}$ dependence. The crystal structure of the fluoride-inhibited SPU enzyme (PDB code 
4CEX) revealed the presence of two fluoride anions bound to the dinickel cluster (Fig. 5a): one fluoride replaces the bridging solvent molecule, as already suggested by Hausinger and co-workers [72], while an additional fluoride replaces the water molecule terminally bound to $\mathrm{Ni}(1)$ [62]. The authors assigned to the anion bound to $\mathrm{Ni}(1)$ the competitive role, contending with urea for this site, and to the anion in the Ni-bridging position an uncompetitive role as replacing the co-substrate in the reaction, namely the bridging hydroxide, would require.

\section{At last, the urease-fluoride-urea complex (2019)}

The structural and kinetic information obtained by studying the inhibition of SPU by fluoride suggested experiments aimed at obtaining a ternary complex between SPU, fluoride and urea by co-crystallizing SPU in the presence of urea upon pre-incubation of the enzyme with fluoride (Fig. 5b) [73]. The experiment worked, and the resulting crystal structure (PDB code 6QDY) represents a breakthrough in the understanding of the catalytic mechanism of urea hydrolysis by urease. The structure unambiguously revealed the presence of a fluoride ion positioned in the nickel-bridging position, confirming the previous observations effected through kinetics $[62,71,72]$ and structural [62] investigations. Most importantly, the structure revealed the presence of a urea molecule replacing $\mathrm{W} 1, \mathrm{~W} 2$ and $\mathrm{W} 3$ and binding $\mathrm{Ni}(1)$ and $\mathrm{Ni}(2)$ in a bidentate mode, using its carbonyl $\mathrm{O}$ atom and its amide $\mathrm{N}$ atom, respectively. The second amide $\mathrm{N}$ atom points away from the $\mathrm{Ni}$ (II) ions, towards the active site channel. As postulated by the "bridging hydroxide mechanism", the urea $\mathrm{O}$ atom receives a hydrogen bond from the protonated $\alpha \mathrm{His} 222 \mathrm{~N} \varepsilon$, structurally demonstrating its direct involvement in the formation of the enzyme-substrate complex, while the interaction between $\mathrm{Ni}(2)$ and the urea $\mathrm{N}$ atom is stabilized by a hydrogen-bond network involving the backbone carbonyl $\mathrm{O}$ atoms of $\alpha \mathrm{Ala} 170$ and $\alpha \mathrm{Ala366}$, whereas the carbonyl $\mathrm{O}$ atoms of $\alpha \mathrm{Gly} 280$ and $\alpha$ Ala366 stabilize the distal urea $\mathrm{N}$ atom through additional $\mathrm{H}$-bonds. This structure clears out any possible doubts associated with this hypothesis, definitely elucidates the coordination mode of urea in the active site cavity, and unambiguously assigns the role of the bridging hydroxide as the nucleophile in the hydrolytic reaction.

In this structure, the mobile flap is observed in the closed conformation, with $\alpha \mathrm{Cys} 322$ and $\alpha \mathrm{His} 323$ placed in close proximity to the urea molecule in the active site. A network of hydrogen bonds, involving $\alpha \mathrm{His} 323 \mathrm{~N} \delta 1$ and $\alpha \mathrm{Asp} 224$ O82, as well as $\alpha \mathrm{His} 323 \mathrm{NH} \varepsilon 2$ and $\alpha \mathrm{Arg} 339 \mathrm{NH} \eta 2$, locks $\alpha$ His323 in the observed position. In this scenario, the described $\mathrm{H}$-bond network imposes that $\alpha \mathrm{His} 323$ must be
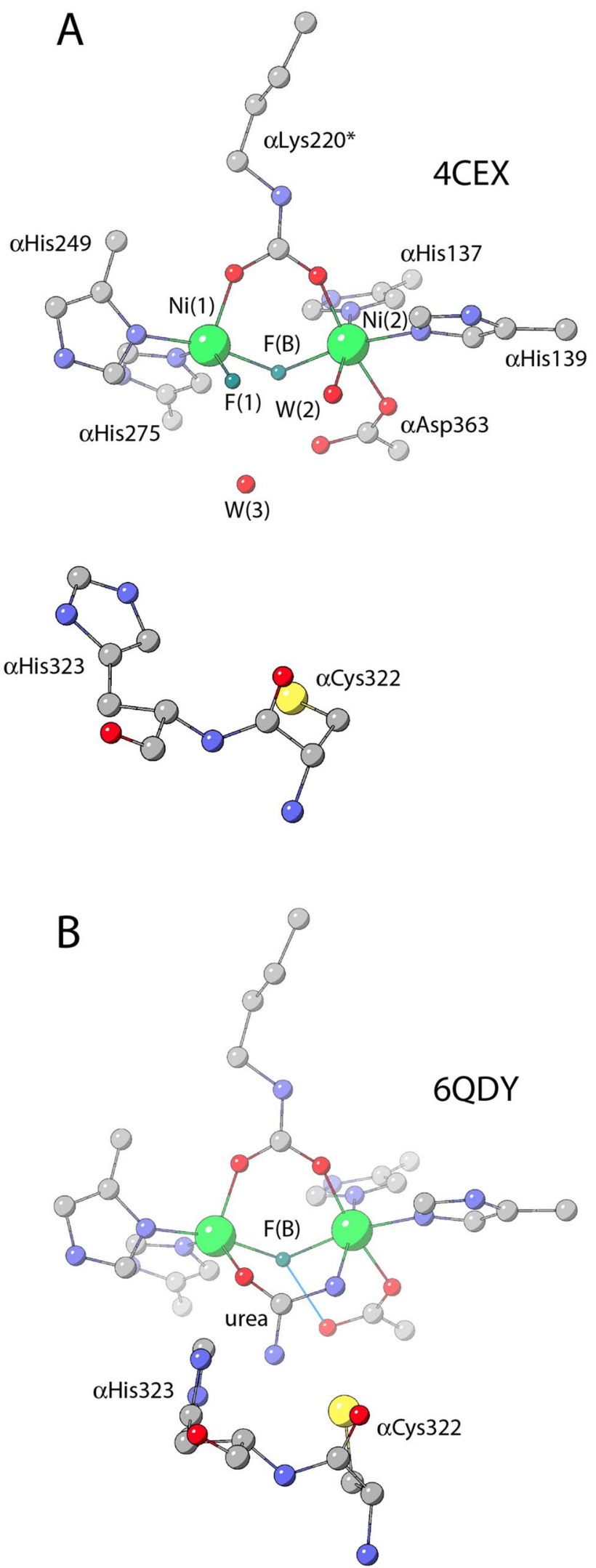

Fig. 5 Model structures of the active site of $S$. pasteurii urease (SPU) as derived from X-ray diffraction data in the fluoride-inhibited state (a PDB code 4CEX), and in the fluoride-inhibited state bound to urea (b PDB code 6QDY) 
neutral, supporting the proposition that $\alpha \mathrm{His} 323$ is required to stabilize a nascent ammonia molecule formed upon proton transfer from the bridging hydroxide to the distal amide group of a Ni-bound urea, prior to the breaking of the $\mathrm{C}-\mathrm{N}$ bond and the release of ammonia. The closing of the flap, which stabilizes the binding of the substrate urea to the $\mathrm{Ni}$ ions in the active site, could happen with a frequency that depends on the $\mathrm{pH}$, with an increased probability to find the flap in the closed conformation as the $\mathrm{pH}$ increases up to its optimum value of 7.8 [70]. It can be envisioned that, after hydrolysis, the flap swings open allowing release of the products and the entry of a new urea molecule to re-start the catalytic cycle.

\section{Conclusion}

Many years have passed since the discovery of a biological role for nickel in the catalysis of urease, opening a breach in the bioinorganic scientific community through which subsequent studies unearthed an ever-increasing number of nickeldependent enzymes. This role has been elucidated through a long and winding road, full of surprises, wrong turns and discoveries at each crossroad. We hope and believe that the evolution of the theories concerning the mechanism of this key enzyme, described and discussed in this mini review, could inspire the new generations of bioinorganic chemists to resolve the mysteries still shrouded in the chemistry of the active sites of other metalloenzymes. In the same context, it is interesting to highlight the close relationship of the structure and chemistry of urease with a number of related metallohydrolases $[74,75]$ such as arginase and agmatinase [76] as well as purple acid phosphatases [77], which feature a similar di-metallic active site containing manganese and iron in place of nickel.

Our contribution is nothing more than an attempt to stimulate the curiosity and interest of our scientific community into the chemical biology of this very ancient element, originated with iron as a major end product of supernova nucleosynthesis, brought to Earth by meteorites, discovered in mid 1700s, given a devilish name, and yet so important for the geo-biochemical cycles of nitrogen, hydrogen, carbon and oxygen, essential elements on which life, as we know it, depends.

\footnotetext{
Acknowledgements This review is a result of the longstanding collaboration between the authors and Professors Stefano Benini (Free University of Bolzano, Italy), Wojciech Rypniewski (Polish Academy of Sciences, Poznan, Poland), Keith Wilson (University of York, UK), Stefano Mangani (University of Siena, Italy), and Michele Cianci (Polytechnic University of Marche, Ancona, Italy). The journey from the early days spent all together at the EMBL Hamburg outstation could not have been more enjoyable ("Let's drink to us..."). Many of the thoughts it contains are the results of the collaboration with these fine
}

scientists, and we thank them for their work, inspiration and friendship. That said, responsibility for the opinions expressed here and whatever errors this review contain rests entirely with the authors.

Funding Open access funding provided by Alma Mater Studiorum Università di Bologna within the CRUI-CARE Agreement.

\section{Compliance with ethical standards}

Conflict of interest The authors declare no conflict of interest.

Open Access This article is licensed under a Creative Commons Attribution 4.0 International License, which permits use, sharing, adaptation, distribution and reproduction in any medium or format, as long as you give appropriate credit to the original author(s) and the source, provide a link to the Creative Commons licence, and indicate if changes were made. The images or other third party material in this article are included in the article's Creative Commons licence, unless indicated otherwise in a credit line to the material. If material is not included in the article's Creative Commons licence and your intended use is not permitted by statutory regulation or exceeds the permitted use, you will need to obtain permission directly from the copyright holder. To view a copy of this licence, visit http://creativecommons.org/licenses/by/4.0/.

\section{References}

1. Hausinger RP (1987) Nickel utilization by microorganisms. Microbiol Rev 51(1):22-42

2. Mobley HL, Hausinger RP (1989) Microbial ureases: significance, regulation, and molecular characterization. Microbiol Rev 53(1):85-108

3. Blakeley RL, Hinds JA, Kunze HE, Webb EC, Zerner B (1969) Jack bean urease (EC 3.5.1.5). Demonstration of a carbamoyltransfer reaction and inhibition by hydroxamic acids. Biochemistry 8(5):1991-2000

4. Dixon NE, Riddles PW, Gazzola C, Blakeley RL, Zerner B (1980) Jack bean urease (EC 3.5.1.5). V. On the mechanism of action of urease on urea, formamide, acetamide, $N$-methylurea, and related compounds. Can J Biochem 58(12):1335-1344

5. Maroney MJ, Ciurli S (2014) Nonredox nickel enzymes. Chem Rev 114(8):4206-4228

6. Mazzei L, Musiani F, Ciurli S (2017) Urease. In: Zamble D, Rowińska-Żyrek M, Kozłowski H (eds) The Biological Chemistry of Nickel. Metallobiology, vol 10. Royal Society of Chemistry, pp 60-97

7. Rutherford JC (2014) The emerging role of urease as a general microbial virulence factor. PLoS Pathog 10(5):e1004062

8. Kiss S, Simihaian M (2002) Improving efficiency of urea fertilizers by inhibition of soil urease activity. Kluwer Academic Publishers, Dordrecht

9. Konieczna I, Zarnowiec P, Kwinkowski M, Kolesinska B, Fraczyk J, Kaminski Z, Kaca W (2012) Bacterial urease and its role in long-lasting human diseases. Curr Protein Pept Sci 13(8):789-806

10. Maier RJ, Benoit SL (2019) Role of nickel in microbial pathogenesis. Inorganics 7(7):80

11. WHO (2017) Global priority list of antibiotic-resistant bacteria to guide research, discovery, and development of new antibiotics. https://www.who.int/medicines/publications/WHO-PPL-Short _Summary_25Feb-ET_NM_WHO.pdf?ua=1

12. Zhou F, Yu T, Du R, Fan G, Liu Y, Liu Z, Xiang J, Wang Y, Song B, Gu X, Guan L, Wei Y, Li H, Wu X, Xu J, Tu S, Zhang Y, Chen H, Cao B (2020) Clinical course and risk factors for mortality of 
adult inpatients with COVID-19 in Wuhan, China: a retrospective cohort study. Lancet 395(10229): 1054-1062

13. Kusters JG, van Vliet AH, Kuipers EJ (2006) Pathogenesis of Helicobacter pylori infection. Clin Microbiol Rev 19(3):449-490

14. Bauerfeind P, Garner R, Dunn BE, Mobley HLT (1997) Synthesis and activity of Helicobacter pylori urease and catalase at low $\mathrm{pH}$. Gut 40(1):25-30

15. Marshall B, Warren JR (1984) Unidentified curved bacilli in the stomach of patients with gastritis and peptic ulceration. Lancet 323(8390):1311-1315

16. Stingl K, Altendorf K, Bakker E (2002) Acid survival of Helicobacter pylori: how does urease activity trigger cytoplasmic $\mathrm{pH}$ homeostasis? Trends Microbiol 10:70-74

17. Zhou C, Bhinderwala F, Lehman MK, Thomas VC, Chaudhari SS, Yamada KJ, Foster KW, Powers R, Kielian T, Fey PD (2019) Urease is an essential component of the acid response network of Staphylococcus aureus and is required for a persistent murine kidney infection. PLoS Pathog 15(1):e1007538

18. Clemens DL, Lee BY, Horwitz MA (1995) Purification, characterization, and genetic analysis of Mycobacterium tuberculosis urease, a potentially critical determinant of host-pathogen interaction. J Bacteriol 177(19):5644-5652

19. Gordon AH, Hart PD, Young MR (1980) Ammonia inhibits phagosome-lysosome fusion in macrophages. Nature 286(5768):79-80

20. Lin W, Mathys V, Ang ELY, Koh VHQ, Martínez Gómez JM, Ang MLT, Zainul Rahim SZ, Tan MP, Pethe K, Alonso S (2012) Urease activity represents an alternative pathway for Mycobacterium tuberculosis nitrogen metabolism. Infect Immun 80:2771-2779

21. Young G, Amid D, Miller V (1996) A bifunctional urease enhances survival of pathogenic Yersinia enterocolitica and Morganella morganii at low $\mathrm{pH}$. J Bacteriol 178:6487-6495

22. Cox GM, Mukherjee J, Cole GT, Casadevall A, Perfect JR (2000) Urease as a virulence factor in experimental cryptococcosis. Infect Immun 68(2):443-448

23. Paulot F, Jacob DJ (2014) Hidden cost of U.S. agricultural exports: particulate matter from ammonia emissions. Environ Sci Technol 48(2):903-908

24. Cui Y, Zhang ZF, Froines J, Zhao J, Wang H, Yu SZ, Detels R (2003) Air pollution and case fatality of SARS in the People's Republic of China: an ecologic study. Environ Health 2(1):15

25. Van Tieghem M (1864) C R Acad Sci 58:210

26. Musculus F (1874) C R Acad Sci 78:132

27. Musculus F (1876) C R Acad Sci 82:333

28. Sumner JB (1926) The isolation and crystallization of the enzyme urease. J Biol Chem 69:435-441

29. Karplus PA, Pearson MA, Hausinger RP (1997) 70 years of crystalline urease: what have we learned? Acc Chem Res 30:330-337

30. Dixon NE, Gazzola C, Blakeley R, Zerner B (1975) Jack bean urease (EC 3.5.1.5). A metalloenzyme. A simple biological role for nickel? J Am Chem Soc 97(14):4131-4132

31. Dixon N (2010) On being at the right place at the right time. Aust Biochemist 41(3):32-35

32. Jabri E, Carr MB, Hausinger RP, Karplus PA (1995) The crystal structure of urease from Klebsiella aerogenes. Science 268:998-1004

33. Benini S, Rypniewski WR, Wilson KS, Miletti S, Ciurli S, Mangani S (1999) A new proposal for urease mechanism based on the crystal structures of the native and inhibited enzyme from Bacillus pasteurii: why urea hydrolysis costs two nickels. Structure 7:205-216

34. Ha NC, Oh ST, Sung JY, Cha KA, Lee MH, Oh BH (2001) Supramolecular assembly and acid resistance of Helicobacter pylori urease. Nat Struct Biol 8(6):505-509
35. Balasubramanian A, Ponnuraj K (2010) Crystal structure of the first plant urease from jack bean: 83 years of journey from its first crystal to molecular structure. J Mol Biol 400(3):274-283

36. Norris R, Brocklehurst K (1976) A convenient method of preparation of high-activity urease from Canavalia ensiformis by covalent chromatography and an investigation of its thiol groups with 2,2'-dipyridyl disulphide as a thiol titrant and reactivity probe. Biochem J 159(2):245-257

37. Dixon NE, Blakeley RL, Zerner B (1980) Jack bean urease (E.C. 3.5.1.5). III. The involvement of active-site nickel ion in inhibition by b-mercaptoethanol, phosphoramidate, and fluoride. Can J Biochem 58:481-488

38. Blakeley RL, Dixon NE, Zerner B (1983) Jack bean urease. VII. Light scattering and nickel(II) spectrum. Thiolate-nickel(II) charge transfer peaks in the spectrum of the b-mercaptoethanolurease complex. Biochim Biophys Acta 744:219-229

39. Hasnain SS, Piggot B (1983) An EXAFS study of jack bean urease, a nickel metalloenzyme. Biochem Biophys Res Commun 112(1):279-283

40. Alagna L, Hasnain SS, Piggot B, Williams DJ (1984) The nickel ion environment in jack bean urease. Biochem $\mathrm{J}$ 220:591-595

41. Clark PA, Wilcox DE (1989) Magnetic properties of the nickel enzyme urease, nickel-substituted carboxypeptidase A, and nickel-substituted carbonic anhydrase. Inorg Chem 28:1326-1333

42. Clark PA, Wilcox DE, Scott RA (1990) X-ray absorption spectroscopic evidence for binding of the competitive inhibitor 2-mercaptoethanol to the nickel sites of jack bean urease. A new Ni-Ni interaction in the inhibited enzyme. Inorg Chem 29:579-581

43. Day EP, Peterson J, Sendova MS, Todd MJ, Hausinger RP (1993) Saturation magnetization of ureases from Klebsiella aerogenes and jack bean: no evidence for exchange coupling between the two active site nickel ions in the native enzymes. Inorg Chem 32:634-638

44. Wang S, Lee MH, Hausinger RP, Clark PA, Wilcox DE, Scott RA (1994) Structure of the dinuclear active site of urease. $\mathrm{X}$-ray absorption spectroscopic study of native and 2-mercaptoethanol-inhibited bacterial and plant enzymes. Inorg Chem 33(8):1589-1593

45. Benini S, Ciurli S, Nolting HF, Mangani S (1996) X-ray absorption spectroscopy study of native and phenylphosphorodiamidate-inhibited Bacillus pasteurii urease. Eur J Biochem 239(1):61-66

46. Todd MJ, Hausinger RP (1991) Identification of the essential cysteine residue in Klebsiella aerogenes urease. J Biol Chem 266(36):24327-24331

47. Martin PR, Hausinger RP (1992) Site-directed mutagenesis of the active site cysteine in Klebsiella aerogenes urease. J Biol Chem 267(28):20024-20027

48. Park I-S, Hausinger RP (1993) Site-directed mutagenesis of Klebsiella aerogenes urease: identification of hystidine residues that appear to function in nickel ligation, substrate binding, and catalysis. Protein Sci 2:1034-1041

49. Park IS, Hausinger RP (1995) Requirement of carbon dioxide for in vitro assembly of the urease nickel metallocenter. Science 267(5201):1156-1158

50. Pearson MA, Overbye Michel L, Hausinger RP, Karplus PA (1997) Structures of Cys319 variants and acetohydroxamate-inhibited Klebsiella aerogenes urease. Biochemistry 36:8164-8172

51. Todd MJ, Hausinger RP (1987) Purification and characterization of the nickel-containing multicomponent urease from Klebsiella aerogenes. J Biol Chem 262(13):5963-5967 
52. Mock WL, Aksamawati M (1994) Binding to thermolysin of phenolate-containing inhibitors necessitates a revised mechanism of catalysis. Biochem J 302(Pt 1):57-68

53. Mock WL, Stanford DJ (1996) Arazoformyl dipeptide substrates for thermolysin. Confirmation of a reverse protonation catalytic mechanism. Biochemistry 35(23):7369-7377

54. Basolo F, Pearson RG (1967) Mechanisms of inorganic reactions, 2nd edn. Wiley, New York

55. Omburo GA, Kuo JM, Mullins LS, Raushel FM (1992) Characterization of the zinc binding site of bacterial phosphotriesterase. J Biol Chem 267(19):13278-13283

56. Ciurli S, Benini S, Rypniewski WR, Wilson KS, Miletti S, Mangani S (1999) Structural properties of the nickel ions in urease: novel insights into the catalytic and inhibition mechanisms. Coord Chem Rev 190-192:331-355

57. Benini S, Rypniewski WR, Wilson KS, Miletti S, Ciurli S, Mangani S (2000) The complex of Bacillus pasteurii urease with acetohydroxamate anion from X-ray data at 1.55 A resolution. J Biol Inorg Chem 5(1):110-118

58. Benini S, Rypniewski WR, Wilson KS, Ciurli S, Mangani S (2001) Structure-based rationalization of urease inhibition by phosphate: novel insights into the enzyme mechanism. J Biol Inorg Chem 6(8):778-790

59. Musiani F, Arnofi E, Casadio R, Ciurli S (2001) Structure-based computational study of the catalytic and inhibition mechanisms of urease. J Biol Inorg Chem 6(3):300-314

60. Benini S, Rypniewski WR, Wilson KS, Mangani S, Ciurli $S$ (2004) Molecular details of urease inhibition by boric acid: insights into the catalytic mechanism. J Am Chem Soc 126(12):3714-3715

61. Benini S, Rypniewski WR, Wilson KS, Ciurli S, Mangani S (1998) The complex of Bacillus pasteurii urease with b-mercaptoethanol from X-ray data at $1.65 \AA$ A resolution. J Biol Inorg Chem 3(4):268-2732

62. Benini S, Cianci M, Mazzei L, Ciurli S (2014) Fluoride inhibition of Sporosarcina pasteurii urease: structure and thermodynamics. J Biol Inorg Chem 19:1243-1261

63. Mazzei L, Cianci M, Benini S, Bertini L, Musiani F, Ciurli S (2016) Kinetic and structural studies reveal a unique binding mode of sulfite to the nickel center in urease. J Inorg Biochem 154:42-49

64. Mazzei L, Cianci M, Musiani F, Ciurli S (2016) Inactivation of urease by 1,4-benzoquinone: chemistry at the protein surface. Dalton Trans 45(13):5455-5459

65. Mazzei L, Cianci M, Contaldo U, Musiani F, Ciurli S (2017) Urease inhibition in the presence of $N$-( $n$-butyl) thiophosphoric triamide, a suicide substrate: structure and kinetics. Biochemistry 56(40):5391-5404
66. Mazzei L, Cianci M, Musiani F, Lente G, Palombo M, Ciurli S (2017) Inactivation of urease by catechol: kinetics and structure. J Inorg Biochem 166:182-189

67. Mazzei L, Cianci M, Gonzalez Vara A, Ciurli S (2018) The structure of urease inactivated by $\mathrm{Ag}(\mathrm{I})$ : a new paradigm for enzyme inhibition by heavy metals. Dalton Trans 47(25):8240-8247

68. Mazzei L, Wenzel MN, Cianci M, Palombo M, Casini A, Ciurli S (2019) Inhibition mechanism of urease by $\mathrm{Au}$ (III) compounds unveiled by X-ray diffraction analysis. ACS Med Chem Lett 10(4):564-570

69. Mazzei L, Cianci M, Contaldo U, Ciurli S (2019) Insights into urease inhibition by $N$-( $n$-Butyl) phosphoric triamide through an integrated structural and kinetic approach. J Agric Food Chem 67(8):2127-2138

70. Mazzei L, Cianci M, Benini S, Ciurli S (2019) The impact of $\mathrm{pH}$ on catalytically critical protein conformational changes: the case of the urease, a nickel enzyme. Chemistry 25:15351-15360

71. Pearson MA, Park IS, Schaller RA, Michel LO, Karplus PA, Hausinger RP (2000) Kinetic and structural characterization of urease active site variants. Biochemistry 39(29):8575-8584

72. Todd MJ, Hausinger RP (2000) Fluoride inhibition of Klebsiella aerogenes urease: mechanistic implications of a pseudo-uncompetitive, slow-binding inhibitor. Biochemistry 39(18):5389-5396

73. Mazzei L, Cianci M, Benini S, Ciurli S (2019) The structure of the elusive urease-urea complex unveils a paradigmatic case of metallo-enzyme catalysis. Angew Chem Int Ed 58(22):7415-7419

74. Wilcox DE (1996) Binuclear metallohydrolases. Chem Rev 96:2435-2458

75. Schenk G, Mitic N, Gahan LR, Ollis DL, McGeary RP, Guddat LW (2012) Binuclear metallohydrolases: complex mechanistic strategies for a simple chemical reaction. Acc Chem Res 45(9):1593-1603

76. Uribe E, Reyes M-B, Martínez I, Mella K, Salas M, TarifeñoSaldivia E, López V, García-Robles M, Martínez-Oyanedel J, Figueroa M, Carvajal N, Schenk G (2020) Functional analysis of the $\mathrm{Mn} 2+$ requirement in the catalysis of ureohydrolases arginase and agmatinase-a historical perspective. J Inorg Biochem 202:110812

77. Schenk G, Mitić N, Hanson GR, Comba P (2013) Purple acid phosphatase: a journey into the function and mechanism of a colorful enzyme. Coord Chem Rev 257(2):473-482

Publisher's Note Springer Nature remains neutral with regard to jurisdictional claims in published maps and institutional affiliations. 